Article

\title{
Hydroxypropyl Methylcellulose-Based Hydrogel Copolymeric for Controlled Delivery of Galantamine Hydrobromide in Dementia
}

\author{
Sidra Bashir ${ }^{1}$, Nadiah Zafar ${ }^{1, *}$, Noureddine Lebaz ${ }^{2}\left(\mathbb{D}\right.$, Asif $^{\text {Mahmood }}{ }^{1}(\mathbb{C}$ \\ and Abdelhamid Elaissari ${ }^{2, *(D)}$ \\ 1 Faculty of Pharmacy, The University of Lahore, Punjab 54000, Pakistan; sidrabashir100@gmail.com (S.B.); \\ asif.mahmood@pharm.uol.edu.pk (A.M.) \\ 2 Univ Lyon, Université Claude Bernard Lyon 1, CNRS, LAGEPP UMR 5007, F-69100 Villeurbanne, France; \\ noureddine.lebaz@univ-lyon1.fr \\ * Correspondence: nadiah.zafar@pharm.uol.edu.pk (N.Z.); abdelhamid.elaissari@univ-lyon1.fr (A.E.)
}

Received: 20 September 2020; Accepted: 23 October 2020; Published: 25 October 2020

\begin{abstract}
The study aims to prepare a smart copolymeric for controlled delivery of Galantamine hydrobromide. The synthesis of the hydrogel was executed through free radical polymerization using HPMC (Hydroxypropyl methylcellulose) and pectin as polymers and acrylic acid as monomer. Cross-linking was performed by methylene bisacrylamide (MBA). HPMC-pectin-co-acrylic acid hydrogel was loaded with Galantamine hydrobromide (antidementia drug) as a model drug for treatment of Alzheimer based dementia. Formulated hydrogels (SN1-SN9) were characterized for Fourier transform-infrared spectroscopy, differential scanning calorimetry, thermogravimetric analysis, $\mathrm{X}$-ray diffraction, and energy dispersive $\mathrm{X}$-ray. Drug loading efficiency, gel fraction, measurements of porosity, and tensile strength were reported. Swelling and release studies were performed at pH 1.2 and 7.4. Drug liberation mechanism was evaluated by applying different release kinetic models. Galantamine hydrobromide was released from prepared hydrogels by Fickian release mechanism. Swelling, gel fraction, porosity, and drug release percentages were found to be dependent on hydroxypropyl methylcellulose, pectin, acrylic acid, and methylene bisacrylamide concentrations. By increasing HPMC amount, swelling was increased from $76.7 \%$ to $95.9 \%$. Toxicity studies were conducted on albino male rabbits for a period of 14 days. Hematological and histopathological studies were carried out to evaluate safety level of hydrogel. Successfully prepared HPMC-pectin-co-acrylic acid hydrogel showed good swelling and release kinetics, which may help greatly in providing controlled release drug effect leading to enhanced patient compliance for dementia patients.
\end{abstract}

Keywords: HPMC; galantamine hydrobromide (GH); pectin; hydrogel; methylene bisacrylamide; dementia

\section{Introduction}

Innovative approaches and advancements in biomedical science help in providing improved drug delivery systems. Formulation of advanced and productive drug delivery systems are a necessity to provide better treatment of different diseases [1]. Oral route is the most acceptable route of drug delivery for the greatest number of patients mainly because of its low cost compared to other dosage forms. Moreover, it is a safe route with an effective outcome and also oral dosage forms are easily ingested. Conventional immediate release oral dosage forms require frequent daily dosing leading to fluctuation of drug level in plasma, which imparts a negative effect on the drug efficacy. Controlled release (CR) tablets are developed not only to surmount the demerits of older oral dosage forms but also to provide other useful advantages [2]. CR systems maintain steady state concentration of drug in plasma and 
thereby reduce the frequency of daily dose. CR tablets usually face the problem of dose dumping when they undergo disintegration process, which results in severe toxicity. Such demerits are usually overcome by using diverse polymers in controlled release systems. Utilization of polymers has highly impacted the advancement of modern medicine and has led towards increased patient compliance [3,4]. Biocompatible polymers are widely employed in controlled release systems, which can release drug over long intervals of time. Polymeric based drug carriers display lesser side effects and also provide potential for site specific drug delivery [5].

Polymers that display changes in their physical characteristics when external stimuli are applied are termed as stimuli-responsive polymers [6]. Such polymers can be employed to achieve any particular targeted area drug release [7]. They are also employed in hydrogels fabrication [8,9]. Hydrogels are 3D polymeric cross-linked network like structures displaying high hydrophilicity. They are also termed as smart or intelligent systems as they are engineered to be sensitive to environmental stimuli. Hydrogels are widely applicable in diverse biomedical, environmental, and pharmaceutical fields, such as tissue engineering, contact lens, immune-therapy, and most importantly in controlled drug release. Their attractive feature of displaying swelling behavior and releasing entrapped drug molecules upon change in $\mathrm{pH}$ and other stimuli such as temperature, light, pressure, and electric field makes them compatible for usage in controlled and targeted drug delivery systems [10]. Free radical polymerization is a widely used method for cross-linking the hydrogels structure [11,12].

Hydroxypropyl methylcellulose (HPMC) is a cellulose derivative, which is water soluble in nature. It is widely employed in many industries like food, plastic, and most importantly, the pharmaceutical industry. Many grades of HPMC are used in formulation of several oral dosage forms. HPMC finds its diverse applications in oral dosages due to its biocompatibility, biodegradability, hydrophilicity, and swelling ability [13].

Pectin is a naturally occurring polysaccharide having a complex structure with hydrophilic characteristic. Pectin is nontoxic, biocompatible, and economic in cost, which is why it has many applications in biotechnology and pharmaceuticals. It has been generally used as stabilizer and gelling agent as well as polymer in hydrogel formation [14].

Galantamine hydrobromide $(\mathrm{GH})$ is an antidementia drug, which is used in treatment of Alzheimer based dementia. Because of its short half-life of $7 \mathrm{~h}$, it is administrated two times a day. Dementia is a neurodegenerative syndrome related to memory loss, mental confusion, and motor dysfunctions. The pharmacological class of Galantamine hydrobromide is cholinesterase inhibitor. It is a reversible competitive inhibitor of acetylcholine esterase. It is metabolized by cytochrome P450, 2D6, and 3A4 enzymes. Drugs that are metabolized through these enzymes affect the pharmacokinetics of Galantamine hydrobromide if they are coadministered [15].

Hydrogels are three dimensional networks that have the ability to absorb a large amount water. These have resemblance to natural tissues because of their soft, elastic nature and low interfacial tension. These are widely employed in the pharmaceutical, agriculture, and medical sector because of their tunable properties, biocompatibility, and gel forming ability. These intelligent networks can be prepared by a number of techniques, but the most widely used approach is aqueous free radical polymerization [16].

In this study, MBA cross-linked HPMC-pectin-co-acrylic acid hydrogels were fabricated by free radical polymerization for controlled delivery of Galantamine hydrobromide. Controlled release oral hydrogels of Galantamine hydrobromide can give a better and more efficient way of administrating the therapeutic amount of drug as a single dose, thereby reducing the frequency of dosing. Such a system shall maintain the steady state drug plasma levels, which would be beneficial for dementia patients as they are much more reluctant to take their medications and also often forget to take their medicines because of their mental condition. In this study, nine hydrogels formulations were prepared by varying the amount of polymers, monomer, and cross-linker. The fabricated hydrogels were evaluated by different characterization tests, and their in vitro drug release profile was studied. 


\section{Materials and Methods}

\subsection{Materials}

Hydroxypropyl methylcellulose (HPMC E-5), pectin, and acrylic acid were purchased from Sigma Aldrich (Darmstadt, Germany). Methylene bis-acrylamide (MBA), ammonium persulfate (APS), potassium phosphate (monobasic), hydrochloric acid, and ethanol were obtained from Merck(Darmstadt, Germany). Galantamine hydrobromide was received as a gift from Reko pharmaceutical Multan road Lahore (Pakistan).

\subsection{Methods}

HPMC-pectin-co-acrylic acid hydrogels were formulated through free radical polymerization. A total of $0.5 \mathrm{~g}$ of HPMC was added slowly to already warm $25 \mathrm{~mL}$ of distilled water. It was stirred until formation of clear solution A. A total of $0.5 \mathrm{~g}$ of pectin was added in small divided portions to 10-15 mL distilled water to get clear solution B. Solution A and B were mixed together under continuous stirring to obtain solution C. At the same time, solutions of ammonium per sulfate (APS) and methylene bisacrylamide (MBA) were also prepared separately. A total of $0.2 \mathrm{~g}$ of APS was mixed in approximately $5 \mathrm{~mL}$ of distilled water. A total of $0.3 \mathrm{~g}$ of MBA was added into water to get a clear solution.

Approximately $15 \mathrm{~mL}$ of acrylic acid were added dropwise into already prepared solution $\mathrm{C}$ under continuous stirring. Next, addition of APS solution followed by addition of MBA solution into solution C. The prepared solution was kept under stirring for 5-10 min followed by sonication for 3-5 min at $5000 \mathrm{rpm}$. Sonication was done to eliminate any dissolved oxygen. Test tubes were filled with hydrogel solution, which were sealed with aluminum foil and again sonicated to ensure complete removal of dissolved oxygen. The test tubes were arranged in test tube stand, and this stand was placed in water bath for heating. Firstly, the temperature was set at $45^{\circ} \mathrm{C}$ for one hour. Later on, the temperature of the bath was increased in the following sequence: $50{ }^{\circ} \mathrm{C}$ for two hours, $55^{\circ} \mathrm{C}$ for three hours, $60{ }^{\circ} \mathrm{C}$ for four hours, and $65{ }^{\circ} \mathrm{C}$ for the next twelve hours. During the above-mentioned time period, free radical polymerization was completed, leading to formation of hydrogels. After twenty-four hours, the test tube stand was removed from bath. Tubes were cooled down at room temperature followed by their careful breakage to recover the prepared hydrogels. Hydrogels were cut by sharp edged blade into discs of specific dimensions. The hydrogel discs were washed with ethanol: water (50:50) solution in order to remove any unreacted species. Discs were transferred into petri dishes and dried at room temperature. Different combinations were prepared by varying quantities of HPMC, pectin, acrylic acid, and MBA (Table 1). Dried hydrogels were stored for further characterization and evaluation process.

Table 1. Composition of Hydroxypropyl methylcellulose (HPMC)-pectin-co-acrylic acid hydrogels formulations (SN1-SN9).

\begin{tabular}{cccccc}
\hline Formulation Codes & HPMC (g) & Pectin $(\mathbf{g})$ & MBA $(\mathrm{g})$ & Acrylic Acid $(\mathbf{m L})$ & APS $(\mathrm{g})$ \\
\hline SN1 & 0.5 & 0.5 & 0.3 & 15 & 0.2 \\
SN2 & 0.5 & 0.5 & 0.5 & 15 & 0.2 \\
SN3 & 0.5 & 0.5 & 0.7 & 15 & 0.2 \\
SN4 & 0.5 & 1 & 0.3 & 15 & 0.2 \\
SN5 & 0.5 & 1.5 & 0.3 & 15 & 0.2 \\
SN6 & 1 & 0.5 & 0.3 & 15 & 0.2 \\
SN7 & 1.5 & 0.5 & 0.3 & 15 & 0.2 \\
SN8 & 0.5 & 0.5 & 0.3 & 17 & 0.2 \\
SN9 & 0.5 & 0.5 & 0.3 & 19 & 0.2 \\
\hline
\end{tabular}

\subsubsection{Drug Loading and Entrapment Efficiency}

Drug loading efficiency of all hydrogel formulations was calculated. Drug was loaded into hydrogels through post loading method in which the hydrogel discs were soaked into $1 \% w / v$ drug 
solution for approximately 1 week. After optimum swelling, discs were removed from the drug solution. Blotting paper was used to remove excess solvent from their surface. Firstly, these swollen discs were dried at room temperature and then dried in an oven at $40-45^{\circ} \mathrm{C}$ for one week or complete drying [16]. Drug loading was determined through the equation below:

$$
\operatorname{Drug} \operatorname{Loading}(\%)=\left(\frac{W_{d}-W_{0}}{W_{d}}\right) \times 100
$$

where $W_{0}$ and $W_{d}$ refer to hydrogel weight before and after soaking, respectively.

\subsubsection{Sol-Gel Fraction}

Gel fraction of hydrogels was determined. Soxhlet extractor was used in which small dried hydrogel preweighed pieces were placed with addition of deionized water. Temperature was set at $100{ }^{\circ} \mathrm{C}$ for $4 \mathrm{~h}$. After extraction of uncross-linked polymer, the hydrogel pieces were removed from Soxhlet apparatus and dried at $40{ }^{\circ} \mathrm{C}$ in an oven [16]. Weight of dried hydrogel pieces was noted. Gel percentage was determined by using the following equations:

$$
\begin{aligned}
& \text { Gel fraction }(\%)=\left(\frac{W_{0}-W_{i}}{W_{0}}\right) \times 100 \\
& \text { Sol fraction }(\%)=100-\text { gel fraction }
\end{aligned}
$$

where $W_{0}$ is initial weight of hydrogel pieces before extraction and $W_{i}$ is weight of dried hydrogel pieces after extraction.

\subsubsection{Fourier Transform Infrared (FTIR) Spectroscopy}

FTIR analysis of all ingredients, i.e., HPMC, pectin, acrylic acid, MBA, Galantamine hydrobromide, and fabricated hydrogels was performed for confirmation of the identity and compatibility of ingredients. Hydrogel discs were crushed and placed on crystal mark of FTIR apparatus. Little force was applied on the sample to make a thin film for FTIR analysis. FTIR spectra of fabricated hydrogels and all employed materials were recorded at $500-4000 \mathrm{~cm}^{-1}$ by using FTIR spectrophotometer (Bruker Tensor 27 series, Bremen, Germany) [17].

\subsubsection{Differential Scanning Calorimetry (DSC)}

DSC test was performed to evaluate the thermal stability of hydrogel formulation over a specific temperature range. Glass transition temperature $\left(\mathrm{T}_{\mathrm{g}}\right)$ and nature of crystallization were evaluated in DSC, which was performed using TA instrument (West, Sussex, UK). A $10 \mathrm{mg}$ sample was placed on aluminum pans. DSC was performed at heating range of $0-500{ }^{\circ} \mathrm{C}$ at heating rate of $20{ }^{\circ} \mathrm{C} / \mathrm{min}$ using constant nitrogen flow of $20 \mathrm{~mL} / \mathrm{min}$ [18].

\subsubsection{Thermogravimetric Analysis (TGA)}

TGA was also carried out to check thermal stability in terms of weight loss percentage of sample by providing heat flow, which reflects the physical and chemical nature of the sample. For TGA analysis, 10mg samples were analyzed using TA instrument SDT Q600 (West, UK). Grounded samples were subjected to a temperature range of $0-500{ }^{\circ} \mathrm{C}$ and the heating rate was $10^{\circ} \mathrm{C} / \mathrm{min}$ under a nitrogen purge $(25 \mathrm{~mL} / \mathrm{min})$ [19].

\subsubsection{Powered X-ray Diffraction (PXRD)}

XRD was performed for determining the crystalline or amorphous nature of the samples (Galantamine hydrobromide, HPMC, pectin, and prepared hydrogel) at room temperature under a voltage of $40 \mathrm{kV}$ by 
using an X-ray diffractometer (Siemens model D500, Cu Ka radiation). Diffractogram was scanned at $2 \theta$ angle range of $60-50^{\circ}$ at speed of $2^{\circ} / \mathrm{min}[20]$.

\subsubsection{Energy Dispersive X-ray (EDX) Spectroscopy}

EDX was performed for identification of elemental composition of prepared hydrogels. Atoms of each element emit specific X-rays, which were used for identification of elements of each sample. An EDX analyzer (Model EX-400; Japan) was used for recording EDX peaks of Galantamine hydrobromide, HPMC-pectin-co-acrylic acid hydrogel and Galantamine hydrobromide loaded HPMC-pectin-co-acrylic acid hydrogel [21].

\subsubsection{Porosity Test}

To find the percentage of porosity, weight of hydrogel discs was noted and then dipped into absolute ethanol overnight. Weight of disc was noted again after removing excess ethanol from discs. Porosity \% test was performed for all hydrogel formulations and calculated as:

$$
\text { Porosity }(\%)=\left(\frac{M_{2}-M_{1}}{\rho \mathrm{V}}\right) \times 100
$$

where $M_{1}$ and $M_{2}$ are hydrogel mass before and after dipping into absolute ethanol respectively, $\rho$ is the absolute ethanol density, and V is the hydrogel disc volume.

\subsubsection{Mechanical Strength}

Mechanical strength test was performed by using universal testing machine (UTM) (Instron 3367, Norwood, MA, USA). Freshly prepared hydrogel was placed in UTM jaws and Young's modulus and force in Newton (N) was noted at a point where hydrogel was broken [22].

\subsubsection{Swelling Studies}

Swelling studies were performed at two $\mathrm{pH}$ values, i.e., at 1.2 and 7.4. Dried hydrogel discs of all formulations were weighed and dipped into $200 \mathrm{~mL}$ of respective $\mathrm{pH}$ buffer solutions. After specified time intervals ranging from 0.5 to $72 \mathrm{~h}$, the discs were taken out from buffer solutions and placed onto filter paper for absorption of excessive buffer. Their weight was noted until constant weight was reached. This process was carried out for all hydrogel formulations. Swelling study was conducted for three consecutive days, and percentage was determined through the following formula:

$$
\% \text { of equilibrium swelling }=\left(\frac{W_{s}-W_{i}}{W_{s}}\right) \times 100
$$

where $W_{s}$ is the weight of swollen disc at a specific time interval and $W_{i}$ is its dry weight.

\subsubsection{Galantamine Hydrobromide Release Study}

Release study of Galantamine hydrobromide from HPMC-pectin-co-acrylic acid hydrogel was performed at $\mathrm{pH} 1.2$ and 7.4. Dissolution apparatus II (USP) was used at $50 \mathrm{rpm}$, and a temperature of $37^{\circ} \mathrm{C}$ was maintained. Drug loaded hydrogel discs were placed in $900 \mathrm{~mL}$ of buffer of respective $\mathrm{pH}$, and samples were withdrawn after definite time intervals ranging from 0.5 to $36 \mathrm{~h}$. Absorbance was measured by UV-spectrophotometer (UV-1800, Kyoto, Japan) at $287 \mathrm{~nm}$ [16].

\subsubsection{Release Kinetics}

Data obtained from in vitro drug release process were evaluated to determine the corresponding kinetic model. Dissolution profile data can be interpreted by some mathematical functions, and each function has its own features [23]. 
Zero order kinetics:

$$
Q_{t}=Q_{o}-K_{o} t
$$

First order kinetics:

$$
\operatorname{Ln} Q_{t}=\operatorname{Ln} Q_{o}-K_{1} t
$$

Higuchi Kinetics:

$$
Q_{t}=K_{h} t^{1 / 2}
$$

$Q_{o}$ : Initial amount of drug in hydrogel microparticles,

$Q_{t}$ : Amount of drug after time ' $t$ '

$K_{o}, K_{1}$, and $K_{h}$ are rate constants.

Korsemeyer-Peppas kinetics:

$$
\frac{M_{t}}{M_{\text {inf }}}=K_{p} t^{n}
$$

\subsubsection{Acute Oral Toxicity Studies}

Toxicity study was conducted as per organization for economic cooperation and development (OECD) guidelines on rabbits for examining the safety profile of fabricated HPMC-pectin-co-acrylic acid hydrogels. All the study protocols were reviewed and approved by Institutional Research Ethics Committee of Faculty of Pharmacy, The University of Lahore notification no. IREC-2019-100. Twelve albino male rabbits were divided into two groups named as controlled and tested groups. Each rabbit in both groups has a weight ranging from 1.5 to $2 \mathrm{~kg}$. Healthy food and water were supplied to both groups on a daily basis. The tested group was given a dose of crushed carrier system according to dose of $2 \mathrm{~g} / \mathrm{kg}$. Weight and physical activities were checked on daily basis for 2 weeks. After this time, blood samples were taken from the two groups for different biochemical analysis tests. Then they were sacrificed to remove vital organs, i.e., lungs, brain, heart, liver, small intestine, stomach, and spleen for histopathological examination [24].

\section{Results and Discussion}

\subsection{FTIR Analysis}

Pectin IR peaks are illustrated in Figure 1a. The spectrum has prominent and evident peaks at 3363, 1720, 1602 , and at $1224 \mathrm{~cm}^{-1}$ representing $-\mathrm{OH}$ stretch, stretching of ester carbonyl group (>Carbon=Oxygen), Carbon=Carbon, and Carbon-Oxygen stretching vibration, respectively. Pectin spectrum is confirmed by a literature study conducted by Rehmani et al. [25], who developed semi-interpenetrating hydrogel for delivery of active agents in control kinetics. They studied FTIR spectrum of pectin and found characteristic peaks at $3368,1737,1227$, and at $1605 \mathrm{~cm}^{-1}$.

FTIR spectrum of HPMC E-5 shown in Figure 1b, displays characteristics peaks at 3519, 2867, 1386, and $1045 \mathrm{~cm}^{-1}$, revealing the presence of hydroxyl group $(\mathrm{OH})$ stretching, $\mathrm{C}-\mathrm{H}$ group, vibration of hydroxyl group $(\mathrm{OH})$, and $\mathrm{C}-\mathrm{O}$ group stretching, respectively. Spectrum of HPMC is confirmed through a literature study performed by Akhlaq et al. [26]. They observed characteristic peaks at 3421.48, 2891.10, and at $1377 \mathrm{~cm}^{-1}$.

Galantamine hydrobromide FTIR spectrum illustrated in Figure 1c shows a prominent peak at $3561.87 \mathrm{~cm}^{-1}$ because of $\mathrm{O}-\mathrm{H}$ stretching of enol group $(\mathrm{C}=\mathrm{C}-\mathrm{O}-\mathrm{H})$. Another characteristic peak occurring at $1623.769 \mathrm{~cm}^{-1}$ represented $\mathrm{N}-\mathrm{H}$ bending. Peaks at 1141.625 and $600-700 \mathrm{~cm}^{-1}$ represent $\mathrm{C}-\mathrm{N}$ stretch and $\mathrm{C}-\mathrm{Br}$ bond, respectively. Hanafy et al. [27] have prepared Galantamine hydrobromide loaded chitosan nanoparticles administered through nasal routes for Alzheimer's disease. FTIR analysis showed characteristic peaks at $3559 \mathrm{~cm}^{-1}$ for $\mathrm{O}-\mathrm{H}$ stretching. 


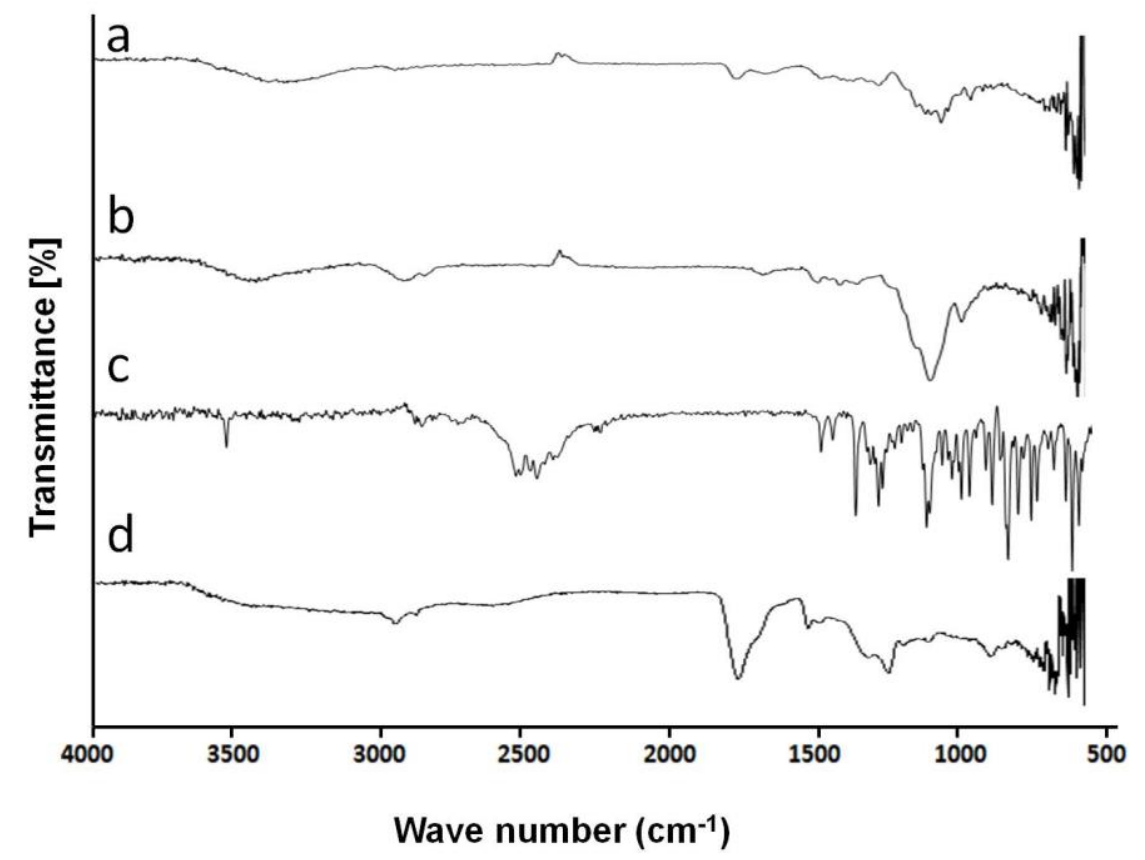

Figure 1. FTIR spectrum of (a) Pectin, (b)HPMC, (c) Galantamine hydrobromide, and (d) hydrogel formulation.

Peaks in IR spectrum of acrylic acid appearing at 1634.74 and $1705.45 \mathrm{~cm}^{-1}$ represented Carbon=Carbon and $\mathrm{C}-\mathrm{O}$ vibrations. These results are verified through literature in a study conducted by Feng et al. [28] who prepared $\mathrm{pH}$-sensitive particles based on polymeric systems for controlled delivery of rebar inhibitor. They observed FTIR peaks of acrylic acid appearing at 1626 and $1707 \mathrm{~cm}^{-1}$.

Infrared spectrum of MBA given showed characteristic peaks at 3308.1, 1666.2, 1530.24, 1408.77, 1379.45 , and $1220.25 \mathrm{~cm}^{-1}$. These peaks are caused by the presence of Carbon=Oxygen bond and Nitrogen-Hydrogen groups. Similar results are reported by Ibrahim [29] who prepared grafted polyacrylamide/chitosan-based hydrogel. They also found IR peaks of MBA at 3305.05, 1656.84, 1537.12, 1382.45 , and $1224.89 \mathrm{~cm}^{-1}$.

IR Spectrum of unloaded formulation of HPMC-pectin-co-acrylic acid hydrogel is shown in Figure 1 d. It shows peaks at 786, 1157, 1444, 1693, and $2915 \mathrm{~cm}^{-1}$, respectively. There is an appearance of new peaks, which confirmed the formation of hydrogel structure.

\subsection{Swelling Studies}

\subsubsection{Influence of MBA on Swelling Percentage}

Swelling studies of HPMC-pectin-co-acrylic acid hydrogel formulations were conducted at $\mathrm{pH} 7.4$ and $\mathrm{pH} 1.2$ for $72 \mathrm{~h}$, which is the equilibrium stage of swelling for these hydrogels. Figure 2a shows that by increasing MBA concentration from 0.5 to $0.7 \mathrm{~g}$, swelling percentage was decreased from 84.62 to $48.25 \%$ at $\mathrm{pH}$ 7.4. A higher cross-linker amount resulted in formation of highly interlaced and dense network having high crosslinking density, which displayed low swelling behavior. At pH 1.2, the swelling percentage was only up to $10 \%$ because acrylic acid is a $\mathrm{pH}$ responsive monomer and it undergoes ionization only at $\mathrm{pH} 7.4$ and remains in unionized state at $\mathrm{pH} 1.2$, thereby no chain relaxation in terms of swelling was observed. 

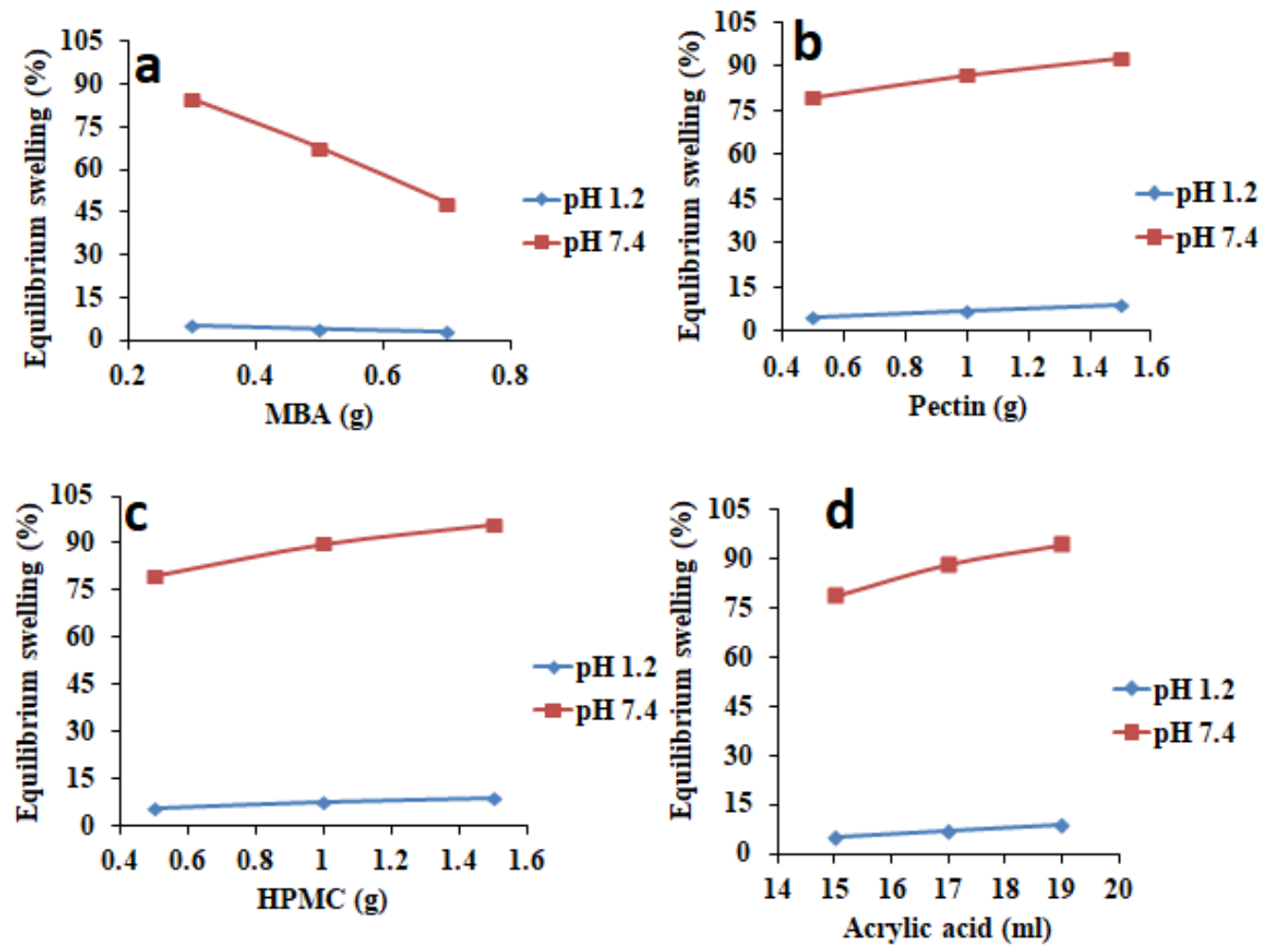

Figure 2. Influence of variable amounts of (a) methylene bisacrylamide (MBA), (b) pectin, (c) HPMC, and (d) acrylic acid on swelling percentage of fabricated hydrogels.

\subsubsection{Influence of Pectin on Swelling Percentage}

Figure $2 \mathrm{~b}$ shows swelling behavior at $\mathrm{pH} 7.4$ of formulations in which pectin amount was increased from 0.5 to $1.5 \mathrm{~g}$. Results had revealed that if higher pectin quantity was used, swelling percentage was also increased from 79.58 to $92.62 \%$ at $\mathrm{pH}$ 7.4. There were two main reasons behind this increased swelling pattern. Firstly, pectin contains carboxymethyl groups $\left(-\mathrm{COOCH}_{3}\right)$, which has greater tendency for ionization at $\mathrm{pH}$ 7.4. When $\left(-\mathrm{COOCH}_{3}\right)$ groups become ionized, electrostatic repulsions occur between them. Such repulsions cause expansion of hydrogel network. Secondly, high porosity was observed by increasing pectin amount at $\mathrm{pH}$ 7.4. So, due to high porosity, more solvent influx occurred into the hydrogel resulting in a high swelling percentage. At $\mathrm{pH}$ 1.2, it was observed that swelling percentage was up to $10 \%$, which was considered as a negligible result because at this $\mathrm{pH}$, carboxymethyl groups $\left(-\mathrm{COOCH}_{3}\right)$ do not ionize, resulting in low to negligible swelling.

\subsubsection{Influence of HPMC on Swelling Percentage}

By increasing HPMC amount from 0.5 to $1.5 \mathrm{~g}$ (Figure 2c), swelling percentage was increased from $76.68 \%$ to $95.89 \%$ at $\mathrm{pH}$ 7.4. Swelling was increased because of the hydrophilic nature of the polymer, which in turn showed excellent swelling potentials. HPMC contains numerous hydroxyl group $(-\mathrm{OH})$, which promote swelling at $\mathrm{pH}$ 7.4. At $\mathrm{pH} 1.2$, swelling percentage was observed up to $10 \%$, which was considered as negligible. Ionization of hydroxyl group $(-\mathrm{OH})$ does not occur at $\mathrm{pH} 1.2$, leading to negligible swelling.

\subsubsection{Influence of Acrylic Acid on Swelling Percentage}

Figure $2 \mathrm{~d}$ shows swelling of formulations in which the amount of acrylic acid was increased gradually from 15 to $19 \mathrm{~mL}$. Swelling percentage range was $78.69-94.38 \%$ at $\mathrm{pH} 7.4$. Results had revealed that increased swelling was seen at basic $\mathrm{pH}$ 7.4. Ionized carboxylic groups of acrylic acid had triggered network swelling at higher $\mathrm{pH}$, i.e., 7.4. So, by increasing acrylic acid amount, more carboxylic 
groups were obtained in ionized form at $\mathrm{pH}$ 7.4. At $\mathrm{pH}$ 1.2, very low swelling percentages were observed, which was considered as negligible, as carboxylic groups do not ionize at acidic $\mathrm{pH}$.

\subsection{Drug Loading Efficiency}

Drug loading efficiency was established to find out the drug percentage entrapped in hydrogel discs. Impact of MBA, pectin, HPMC, and acrylic acid contents on drug loading efficiency is also discussed below.

\subsubsection{Influence of Cross-Linker on Drug Loading Efficiency}

It was found that when concentration of cross-linker (MBA) was increased from 0.3 to $0.7 \mathrm{~g}$, entrapment efficiency was decreased from $89.59 \%$ to $64.25 \%$, respectively (Figure 3a). The reason behind this low entrapment efficiency was because of the decreasing space availability between polymeric chains as the concentration of MBA increased. This compactness between two polymer chains was due to high cross-linker contents. Extremely cross-linked hydrogels cannot expand much (low swelling). Hence, hydrogels containing higher concentration of cross-linker displayed poor swelling and less Galantamine hydrobromide loading.
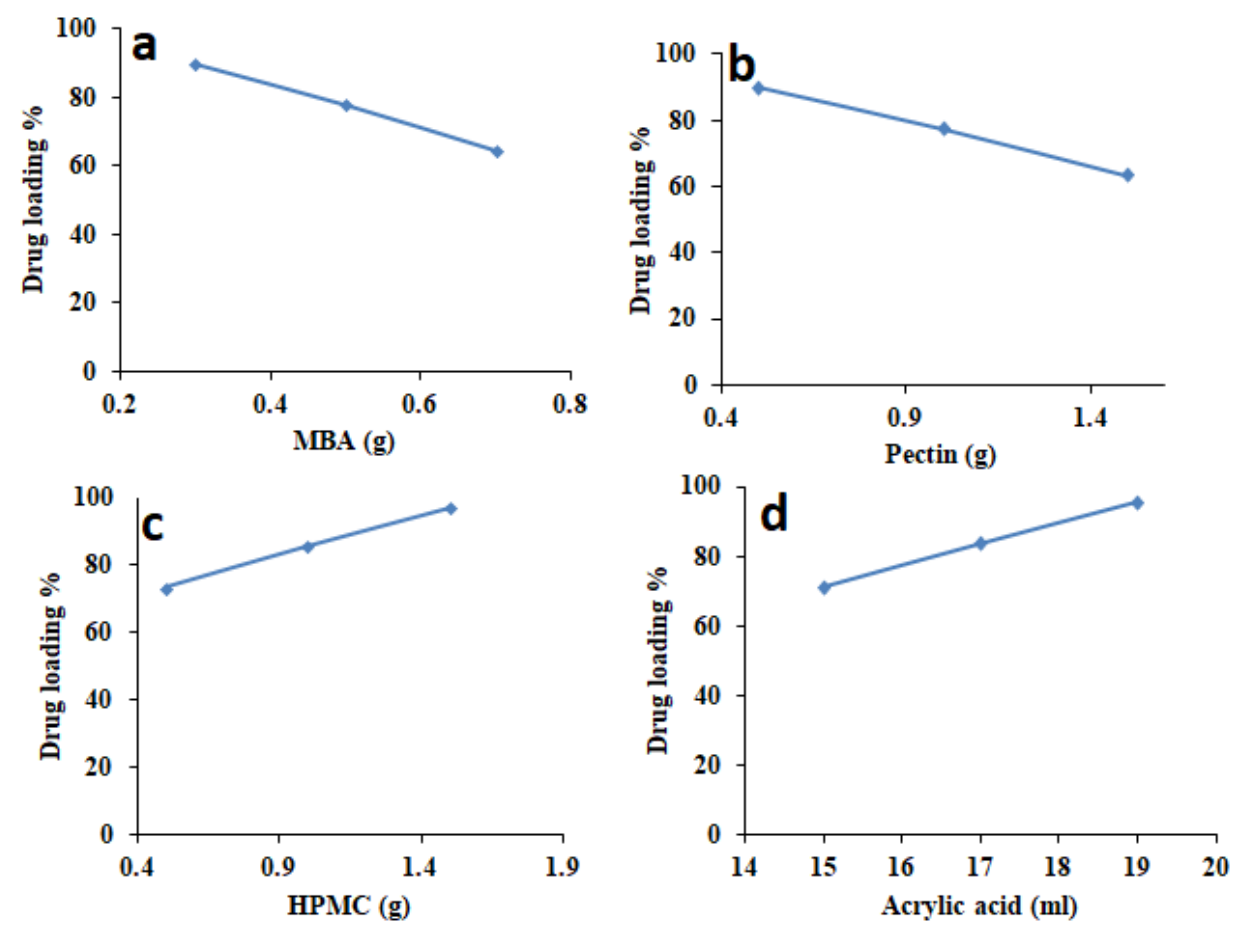

Figure 3. Effect of amount (a) MBA, (b) pectin, (c) HPMC, and (d) acrylic acid on drug loading efficiency.

\subsubsection{Influence of Pectin on Drug Loading Efficiency}

The effect of increasing pectin concentration on drug loading efficiency was also investigated (Figure 3b). It was found that loading efficiency of Galantamine hydrobromide was decreased from $90 \%$ to $63.51 \%$ as concentration of pectin was increased from 0.5 to $1.5 \mathrm{~g}$. Generally, it is observed that hydrogels displaying maximum/more swelling also display maximum/more drug loading efficiency, but such findings were found to be not applicable in the case of pectin. By increasing pectin concentration, even though swelling was increased, drug loading efficiency was decreased. Higher contents of pectin result in a highly viscous diffusion control film/coat that offers resistance in transport of drug models into the developed network. Moreover, the size of Galantamine hydrobromide molecule is larger than water molecules, hence low drug loading was observed. 


\subsubsection{Influence of HPMC on Drug Loading Efficiency}

When concentration of HMPC was increased from 0.5 to $1.5 \mathrm{~g}$, higher drug loading efficiency of Galantamine hydrobromide was observed (Figure 3c). Drug loading efficiency was increased from $73.25 \%$ to $97.15 \%$ due to more hydrophilic character and high swelling capability of HPMC.

\subsubsection{Influence of Acrylic Acid on Drug Loading Efficiency}

Similarly, when the amount of acrylic acid was increased from 15 to $19 \mathrm{~mL}$, drug loading efficiency was increased from $71.26 \%$ to $95.64 \%$, as represented in Figure 3d. Such higher entrapment efficiency was because of higher swelling capability of acrylic acid at pH 7.4.

\subsection{Sol-Gel Fraction}

Influence of variable amounts of MBA, pectin, HPMC, and acrylic acid on sol-gel fraction was investigated, and the results are reported in Figure 4. It was found that increased amount of MBA, pectin, HPMC, and acrylic acid caused increased gel fraction. Figure 4a shows that when MBA amount was increased from 0.3 to $0.7 \mathrm{~g}$, gel fraction was also proportionally increased due to more physical entanglement between polymeric chains leading to eventual more gel formation (83.56-94.25\%). When the pectin amount was increased from 0.5 to $1.5 \mathrm{~g}$, gel fraction was also increased from $82.61 \%$ to $92.36 \%$, as illustrated in Figure $4 \mathrm{~b}$. Gelling ability of pectin is the main reason of this increased gel fraction by increasing pectin concentration. Figure $4 \mathrm{c}$ shows that when HPMC amount was increased from $0.5 \mathrm{~g}$ to $1.5 \mathrm{~g}$, percentage of gel increases from 84.89 to $92.86 \%$. Lastly, results also showed that by increasing acrylic acid concentration, gel fraction was increased from 81.97 to $93.36 \%$ (Figure 4d) because physical entanglement increased by increasing the monomer (acrylic acid) amount.
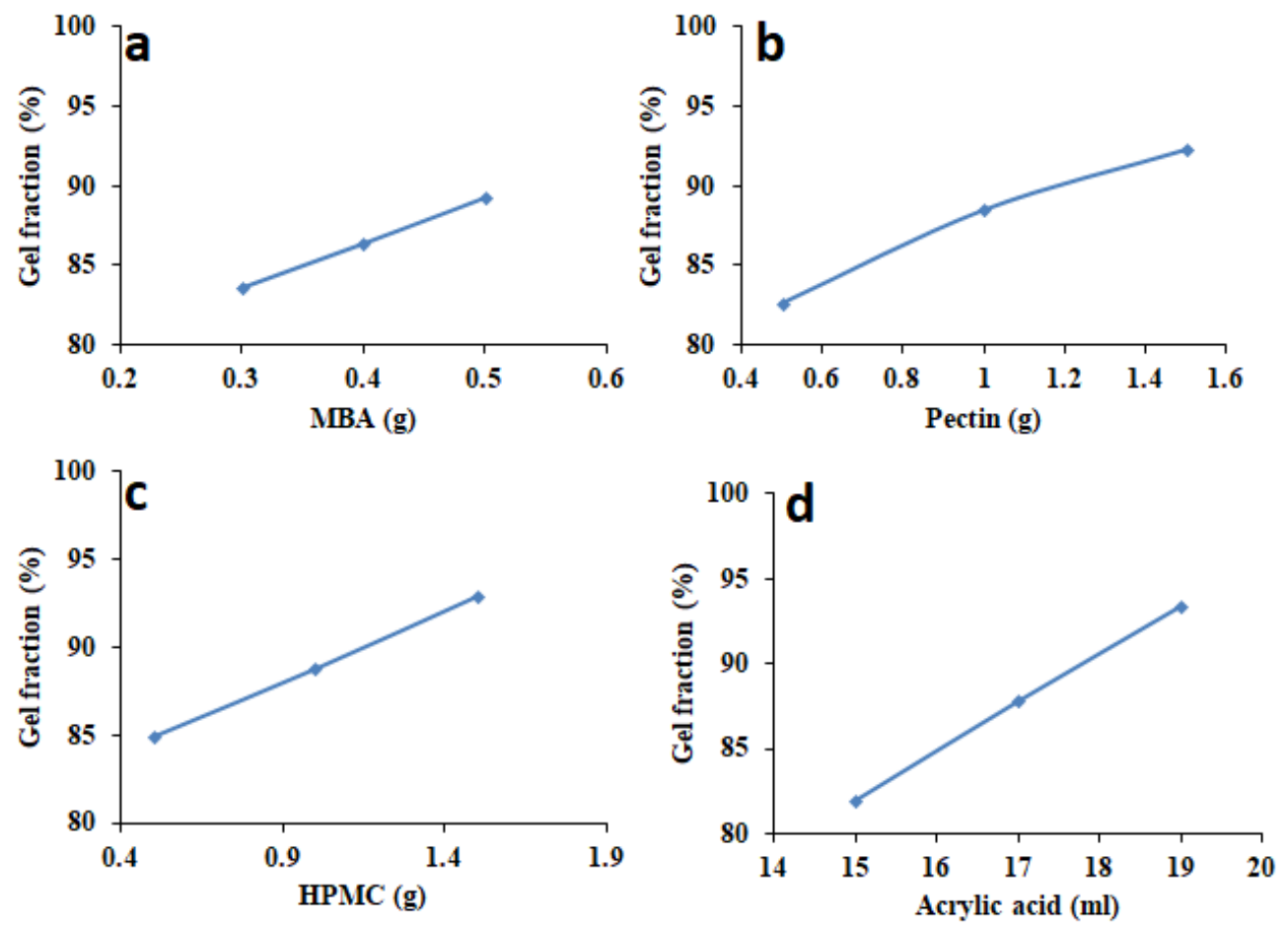

Figure 4. Influence of variable amounts of (a) MBA, (b) pectin, (c) HPMC, and (d) acrylic acid on gel fraction of HPMC-pectin-co-acrylic acid hydrogel.

\subsection{Thermal Analysis}

Thermal analysis is a powerful tool that gives us information about thermal stability of drug, pectin, and prepared hydrogel. DSC and TGA investigations were performed at $0-500^{\circ} \mathrm{C}$ range. Figure 5 presents 
DSC thermograms of Galantamine hydrobromide, pectin, and fabricated hydrogel. Figure 5a displays a small endothermic peak at $280^{\circ} \mathrm{C}$, which represents the melting point of Galantamine hydrobromide. A sharp exothermic peak was shown at $295^{\circ} \mathrm{C}$ due to degradation of drug molecules. DSC thermogram of pectin (Figure 5b) presents first endothermic peak near $110{ }^{\circ} \mathrm{C}$, which is $\mathrm{T}_{\mathrm{g}}$ of pectin and is due to moisture content. One more endothermic peak is observed at $185{ }^{\circ} \mathrm{C}$ due to its melting point. Exothermic peak at $275^{\circ} \mathrm{C}$ was due to complete degradation. Mittal and Kaur [30] reported similar results of thermal analysis of pectin. Thermogram of HPMC-pectin-co-acrylic acid hydrogel is given in Figure 5c. DSC results show that the first endothermic peak occurred at $200^{\circ} \mathrm{C}$ and the second one at $285^{\circ} \mathrm{C}$.

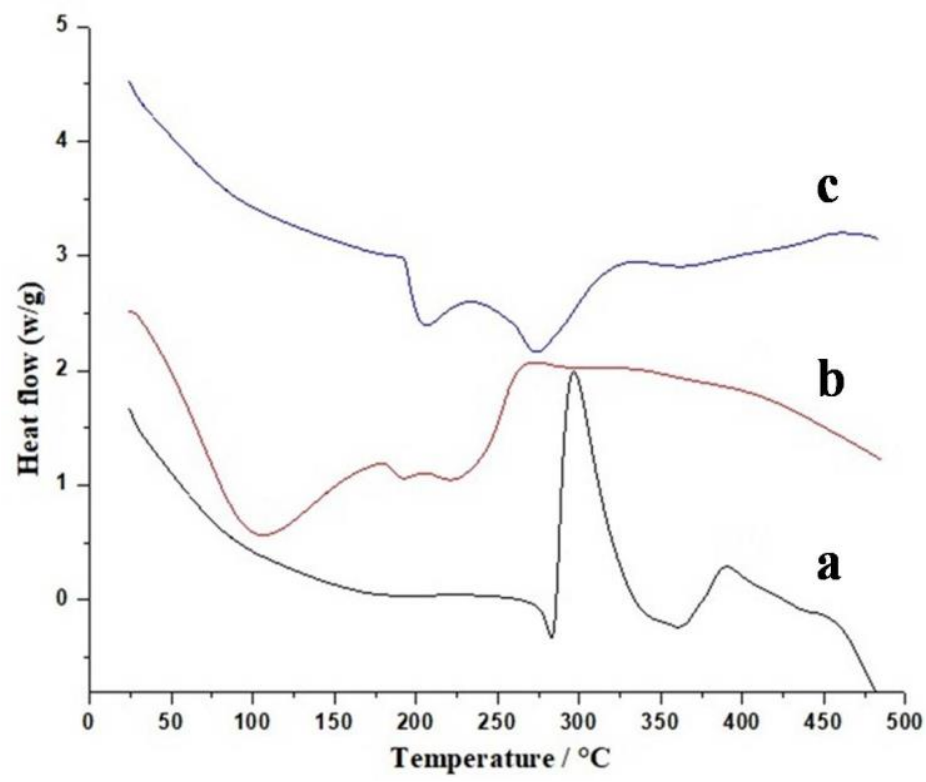

Figure 5. Differential scanning calorimetry (DSC) thermogram of Galantamine hydrobromide (a), pectin, (b) and formulated hydrogel (c).

Figure 6 represents TGA thermograms of Galantamine hydrobromide, pectin, and formulated hydrogel. The TGA thermogram (Figure $6 a$ ) shows that Galantamine hydrobromide model drug reveals initial $10 \%$ mass loss at $285^{\circ} \mathrm{C}$ followed by $50 \%$ mass loss at $375^{\circ} \mathrm{C}$. It was observed from the TGA thermogram of pectin (Figure $6 \mathrm{~b}$ ) that weight loss starts above $200{ }^{\circ} \mathrm{C}$. Initial $10 \%$ weight loss is observed at $240^{\circ} \mathrm{C}$ because of breakage of polymer linkage. At $280{ }^{\circ} \mathrm{C}$, almost $40 \%$ weight loss is noted. Above $300{ }^{\circ} \mathrm{C}$, $60 \%$ weight loss is noted due to complete breakdown of polymer backbone. Hastuti et al. [31] prepared pectin-carboxymethyl chitosan film. They found similar results in TGA analysis. Initial 10\% mass loss occurred at $170{ }^{\circ} \mathrm{C}$, and major mass loss was observed at $285-350{ }^{\circ} \mathrm{C}$. The thermogram of HPMC-pectin-co-acrylic acid hydrogel is given in Figure 6c. The TGA thermogram reveals that the first major weight loss started at $290^{\circ} \mathrm{C}$, and this weight loss continued until $500{ }^{\circ} \mathrm{C}$ where $10 \%$ weight remained. It could easily be concluded that Galantamine hydrobromide loaded hydrogels were more stable as compared to individual formulation ingredients.

\subsection{X-ray Diffraction}

XRD investigation of Galantamine hydrobromide, HPMC, pectin, and HPMC-pectin-co-acrylic acid hydrogel formulation was performed, and the corresponding diffractogram is shown in Figure 7. The Galantamine hydrobromide of diffractogram (Figure 7a) exhibits many characteristic sharp peaks such as at $12.84^{\circ}, 13.56^{\circ}, 17.56^{\circ}$, and $20.76^{\circ}$. These peaks confirm the crystalline nature of the model drug. Figure $7 \mathrm{~b}$ shows the pectin diffractogram, which contains many crystalline sharp peaks at $7.08^{\circ}$, $11.72^{\circ}, 13.16^{\circ}, 18.84^{\circ}, 19.48^{\circ}, 25.16^{\circ}, 27.72^{\circ}$, and $40.28^{\circ}$. Tan et al. [32] have prepared dual interlinked pulp of sago/pectin hydrogel for drug targeting in colon region. Their XRD pectin diffractogram also represents similar crystalline peaks at $8.8^{\circ}, 12.30^{\circ}, 20.2^{\circ}, 27.8^{\circ}$, and $39.4^{\circ}$. Figure $7 \mathrm{c}$ refers to 
HPMC diffractogram, which shows only two distinct peaks at $8.12^{\circ}$ and $20.2^{\circ}$. Similar results were reported by Wang et al. [33] who had fabricated chitosan/HPMC/glycerol-based hydrogel. They also observed only two peaks at $7.9^{\circ}$ and $20.3^{\circ}$ in XRD results of HPMC. Less numbers of crystalline peaks confirmed the amorphous nature of HPMC powder. Figure 7d shows HPMC-pectin-co-acrylic acid hydrogel diffractogram. All characteristic peaks exhibited by pure Galantamine hydrobromide, HPMC, and pectin were observed to be missing from hydrogel diffractogram. This has confirmed that crystalline nature of drug as well as other ingredients was transformed into amorphous nature.

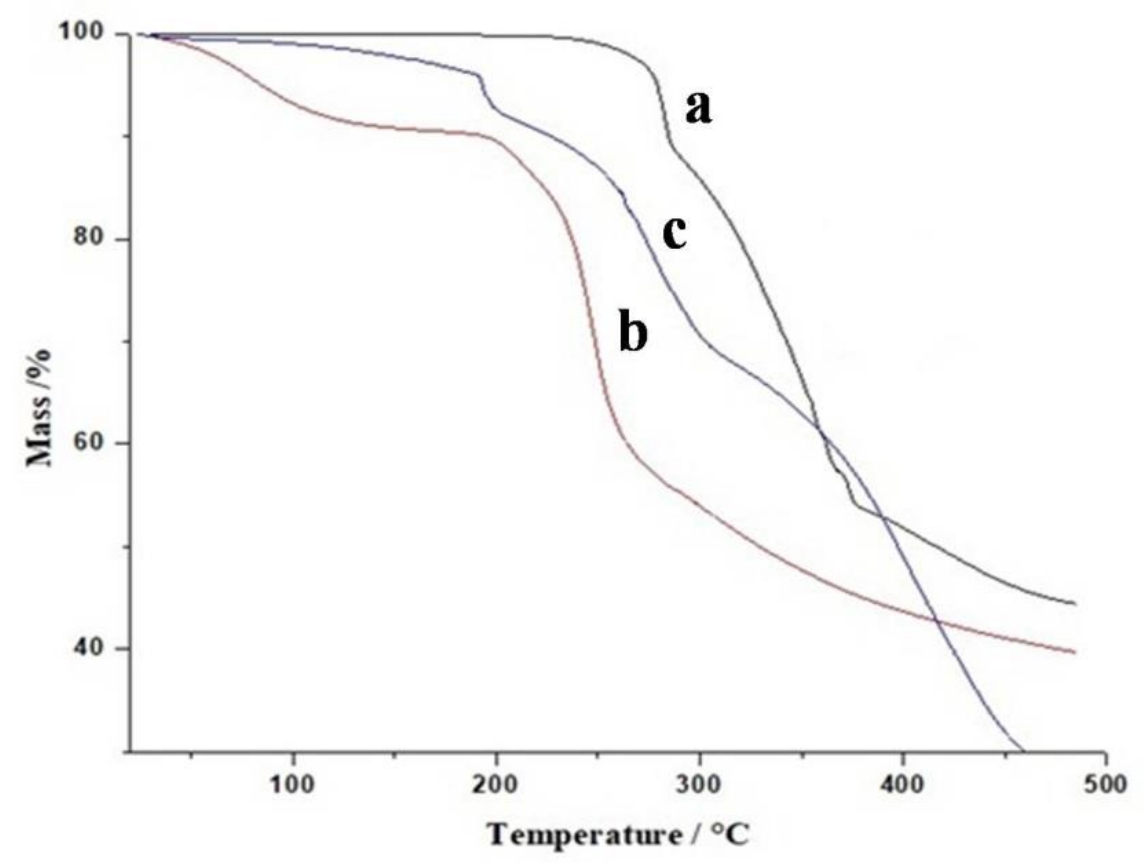

Figure 6. TGA thermogram of Galantamine hydrobromide (a), pectin (b), and formulated hydrogel (c).

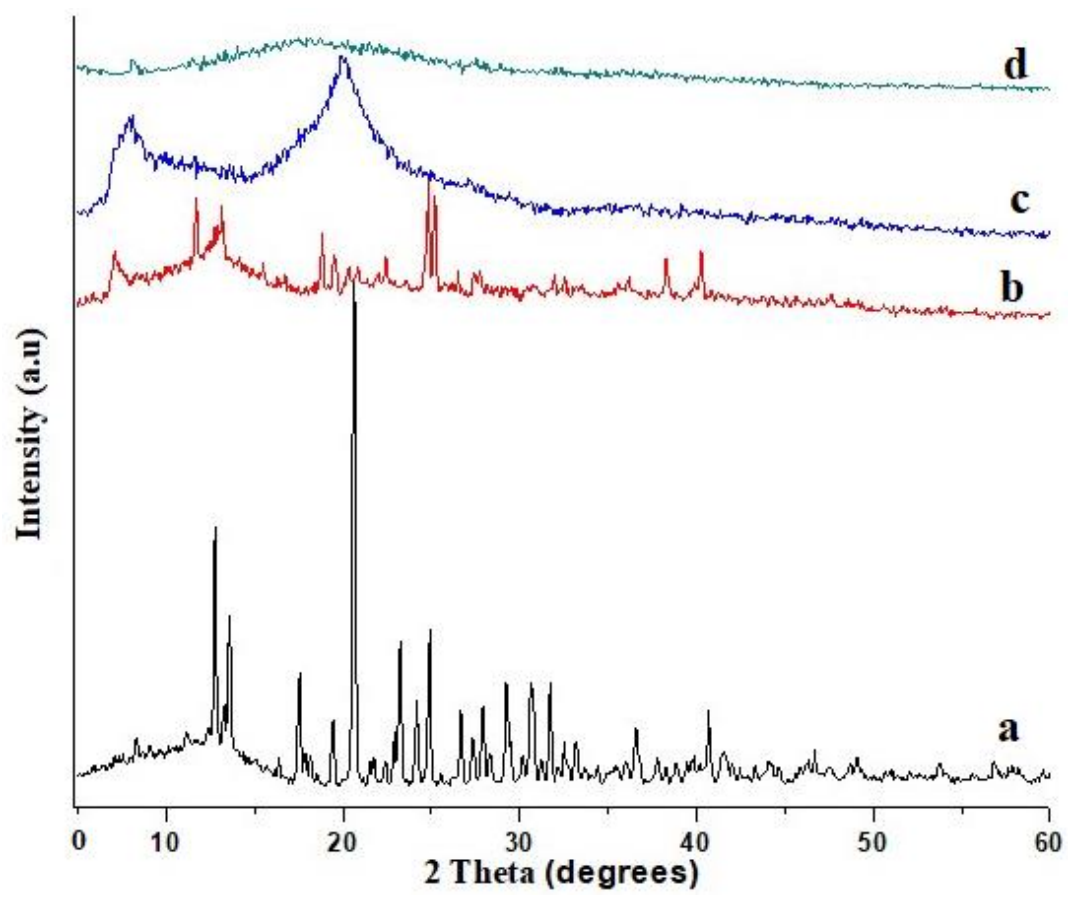

Figure 7. Diffractogram of Galantamine hydrobromide (a), pectin (b), HPMC (c), and formulated hydrogel (d). 


\subsection{Energy Dispersive X-ray Spectrum (EDX) Spectroscopy}

EDX was carried out to identify elemental composition of Galantamine hydrobromide, unloaded hydrogel, and hydrogel loaded with Galantamine hydrobromide. Figure 8a shows EDX spectrum of Galantamine hydrobromide having carbon, oxygen, and bromine elements. Generally, EDX spectrum shows not only presence of particular element but also displays \% weight of each element present in the compound. It was noted that elements of drug were absent in unloaded hydrogels, but bromine was found in EDX spectrum of Galantamine loaded hydrogels. Presence of bromine in case of Galantamine hydrobromide loaded hydrogels ensured successful loading of drug. Percentage of each element is given in Table 2.

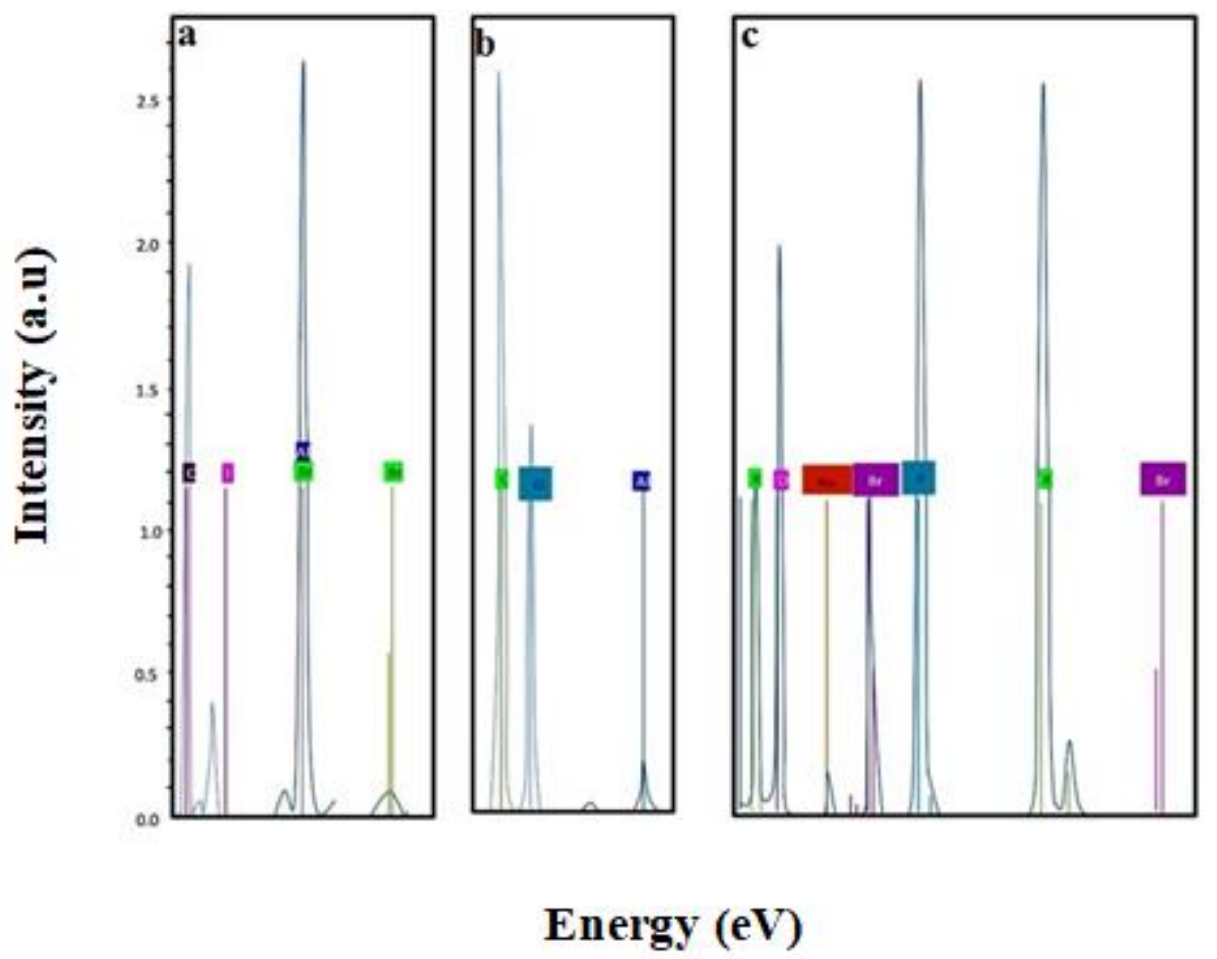

Figure 8. Energy dispersive X-ray (EDX) spectra of Galantamine hydrobromide (a), unloaded hydrogel (b), and drug loaded hydrogel (c).

Table 2. Elemental composition of HPMC-pectin-co-acrylic acid hydrogel.

\begin{tabular}{cccc}
\hline Type of Material & Elements & \% Weight & \% Atomic \\
\hline \multirow{3}{*}{ Galantamine hydrobromide } & Carbon & 51.96 & 76.81 \\
\cline { 2 - 4 } & Oxygen & 10.83 & 12.01 \\
\cline { 2 - 4 } & Bromine & 25.11 & 5.58 \\
\cline { 2 - 4 } Unloaded HPMC-pectin-co-acrylic acid & Nitrogen & 3.64 & 4.61 \\
\cline { 2 - 4 } & Carbon & 51.77 & 59.08 \\
\hline \multirow{2}{*}{ Galantamine hydrobromide loaded } & Oxygen & 47.09 & 40.35 \\
\cline { 2 - 4 } HPMC-pectin-co-acrylic acid & Carbon & 52.83 & 73.82 \\
\cline { 2 - 4 } & Oxygen & 39.99 & 73.82 \\
\cline { 2 - 4 } & Bromine & 2.33 & 0.86 \\
\cline { 2 - 4 } & Sodium & 0.76 & 0.98 \\
\cline { 2 - 4 } & Potassium & 18.73 & 14.15 \\
\hline
\end{tabular}




\subsection{Porosity Measurements}

Porosity of different formulations of HPMC-pectin-co-acrylic acid hydrogel is described in Figure 9. By increasing MBA amount, porosity percentage was decreased from $40.85 \%$ to $29.64 \%$ (Figure 9a) because of high cross-linking density. It was evident from the fact that total swollen volume decreases with the rise of MBA contents, thus a dense and hard structure is achieved. As density has direct relationship with viscosity, viscosity of the network was greatly improved in response to higher MBA contents. Similar findings in respect of porosity, viscosity, and cross-linker feed have been observed in a study conducted by Yoshinobu et al. [34]. By increasing HPMC amount, porosity percentage was increased from 35.02\% to $48.25 \%$ (Figure 9c). By increasing pectin amount, porosity increased from $33.54 \%$ to $47.51 \%$ (Figure $9 b$ ). When quantity of acrylic acid was increased, porosity percent increased from $32.89 \%$ to $44.89 \%$ (Figure 9d). HPMC, pectin, and acrylic acid increase the hydrogel porosity because of increased viscosity of the solution.
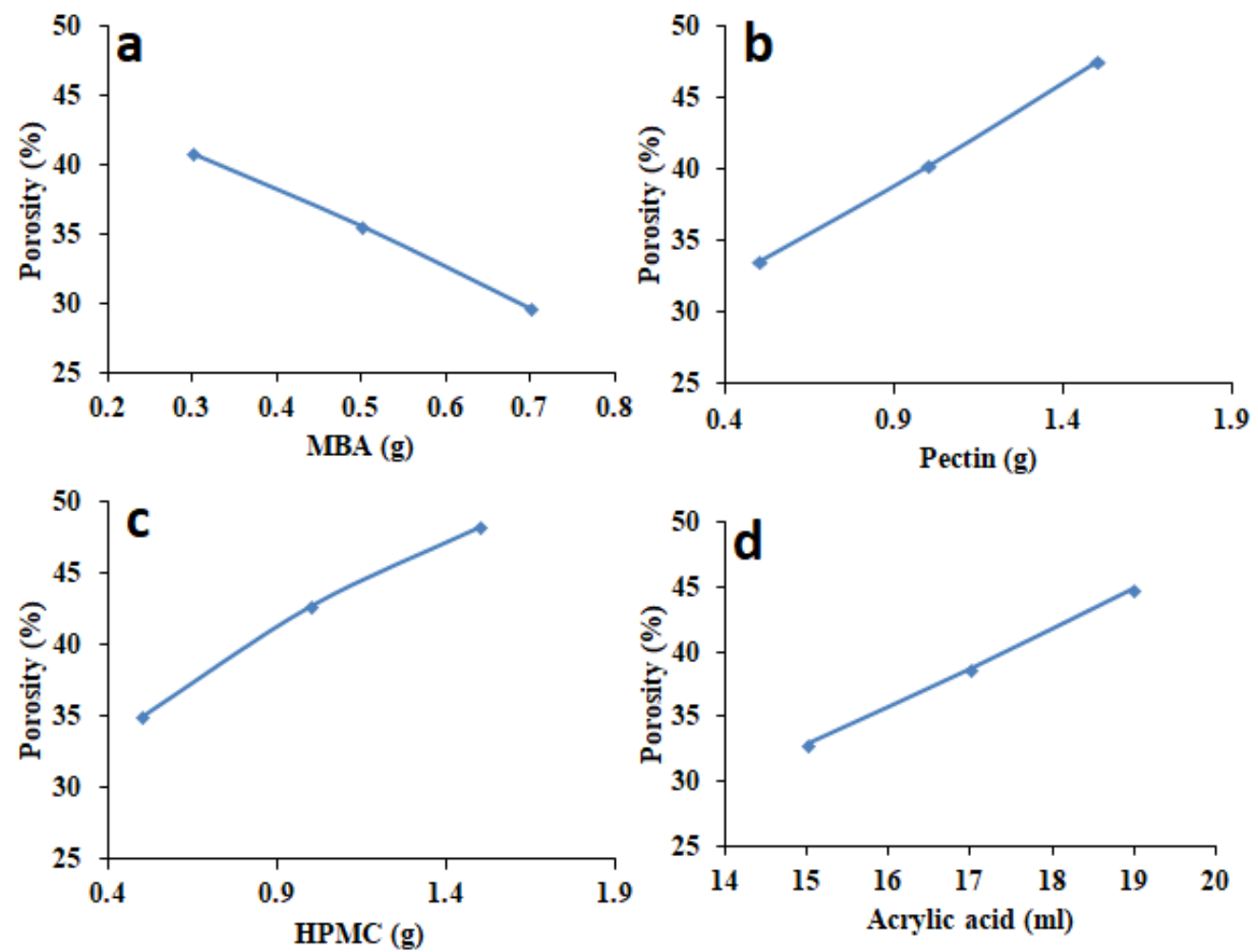

Figure 9. Influence of variable amounts of (a) MBA, (b) pectin, (c) HPMC, and (d) acrylic acid on porosity percentage of formulated hydrogels.

\subsection{Tensile Strength}

Tensile strength of a selected formulation was evaluated by using universal testing machine (UTM) to find out the force at a point where hydrogel breaks. Generally, it is proven from literature that hydrogel formulation, which contains high amount of monomer, would always display the highest amount of tensile strength. Formulation SN9 was selected for testing of tensile strength since it contains the highest amount of acrylic acid $(19 \mathrm{~mL})$ as compared to other prepared formulations. It is found that this formulation displays $11.043 \mathrm{~N} / \mathrm{mm}^{2}$ of tensile strength (Figure 10). Young's modulus was 62.340 N/mm² and percentage of total elongation was 26.464 . 


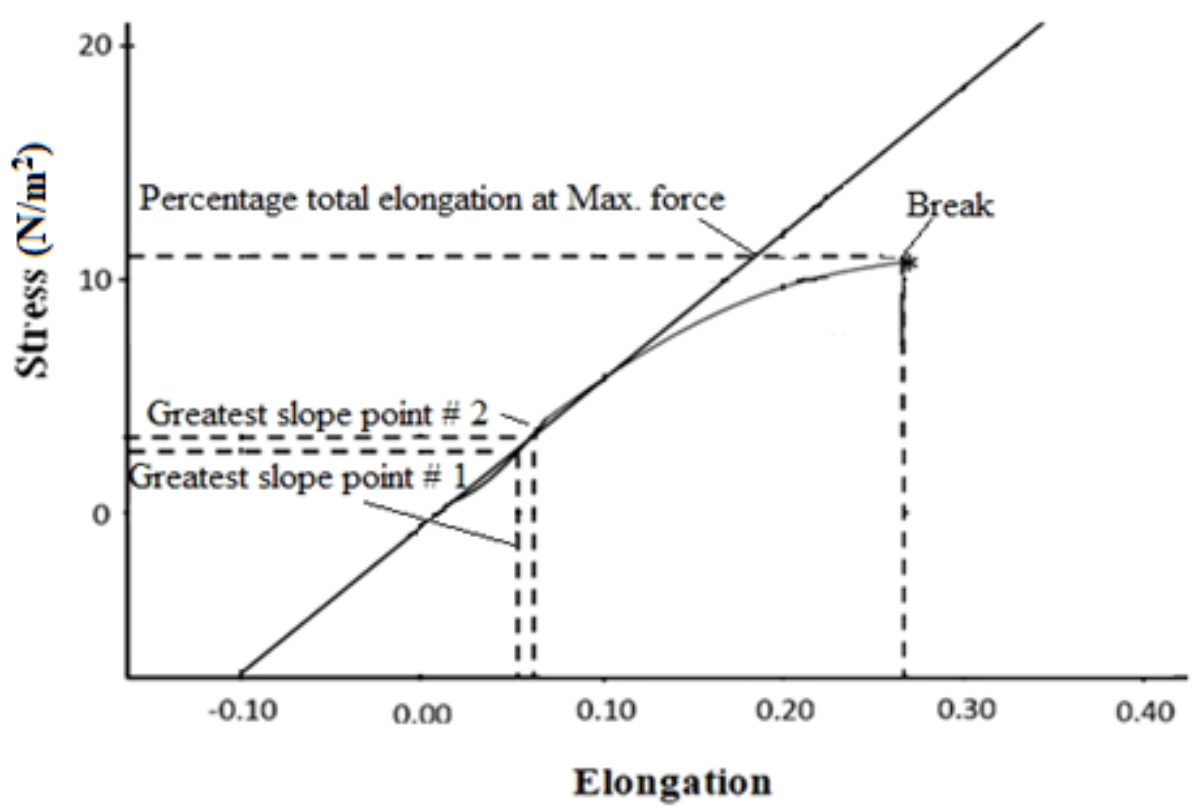

Figure 10. Tensile strength of HPMC-pectin-co-acrylic acid hydrogel.

\subsection{In Vitro Release \% of Galantamine Hydrobromide from HPMC-Pectin-Co-acrylic Acid Hydrogel}

\subsubsection{Influence of MBA Amount on Drug Release Percentage}

This investigation was carried out on dissolution apparatus II for all formulations of HPMC-pectin-co-acrylic acid hydrogels. Drug loaded hydrogels discs were weighed and then immersed into $900 \mathrm{~mL}$ buffers of $\mathrm{pH} 1.2$ and 7.4 individually. Samples were withdrawn after definite time interval from 0 to $36 \mathrm{~h}$ and scanned at $287 \mathrm{~nm}$ wavelength for absorbance. After applying software program DD solver, release kinetics was calculated. The influence of variable amount of MBA on drug release percentage (SN1-SN3) is represented in Figure 11. Drug release percentage was higher at alkaline $\mathrm{pH}$ as compared to acidic. Results showed that when MBA amount was increased, percentage of drug release decreased from $77 \%$ to $66 \%$ at $\mathrm{pH} 7.4$. Increased cross-linker amount caused more physical entanglement resulting in denser hydrogel structure, which hindered drug release from the polymeric network. At $\mathrm{pH} 1.2$, negligible amount of Galantamine hydrobromide was released as compared to $\mathrm{pH}$ 7.4.

\subsubsection{Influence of Pectin Amount on Drug Release Percentage}

Effect of variable pectin amount on percentage of drug release (SN4-SN5) was observed and the results are displayed in Figure 11. As pectin amount increased from 0.5 to $1.5 \mathrm{~g}$, drug release percentage decreased from 78.09 to $66.35 \%$ at $\mathrm{pH}$ 7.4. This behavior was due to increased viscosity upon increasing amount of pectin. There was a formation of gelatinous diffusion control layer, which created a barrier for drug release from the hydrogel network. At $\mathrm{pH} 1.2$, negligible amount of Galantamine hydrobromide was released as compared to $\mathrm{pH}$ 7.4.

\subsubsection{Influence of HPMC and Acrylic Acid Amount on Drug Release Percentage}

HPMC (SN6-SN7) and acrylic acid (SN8-SN9) concentration influences the liberation percentage of Galantamine hydrobromide as observed. Hydrogel discs, when subjected to dissolution studies, were solid and having less volume, but with the passage of time, these were swollen as a result of penetration of buffer media. Moreover, geometry of hydrogel discs remained intact even after dissolution experiments. Formulations containing variable amount of HPMC revealed that as the amount of HPMC was gradually increased from 0.5 to $1.5 \mathrm{~g}$, drug release percentage also simultaneously increased from 75.36 to $87.62 \%$ at $\mathrm{pH} 7.4$. This is due to higher swell-ability and hydrophilic nature 
of HPMC at $\mathrm{pH}$ 7.4. With increase in concentration of HPMC, hydroxyl groups were increased, which have more tendency to absorb water resulting in greater percentage of drug release. At acidic $\mathrm{pH}$, up to $8.3 \%$ Galantamine hydrobromide liberation was observed. Percentage release also increased upon increasing amount of acrylic acid from 15 to $19 \mathrm{~mL}$ at $\mathrm{pH} 7.4$ as compared to $\mathrm{pH} 1.2$ because acrylic acid has carboxylic groups, which led to higher ionization at $\mathrm{pH} 7.4$ providing enhanced swelling and drug release.
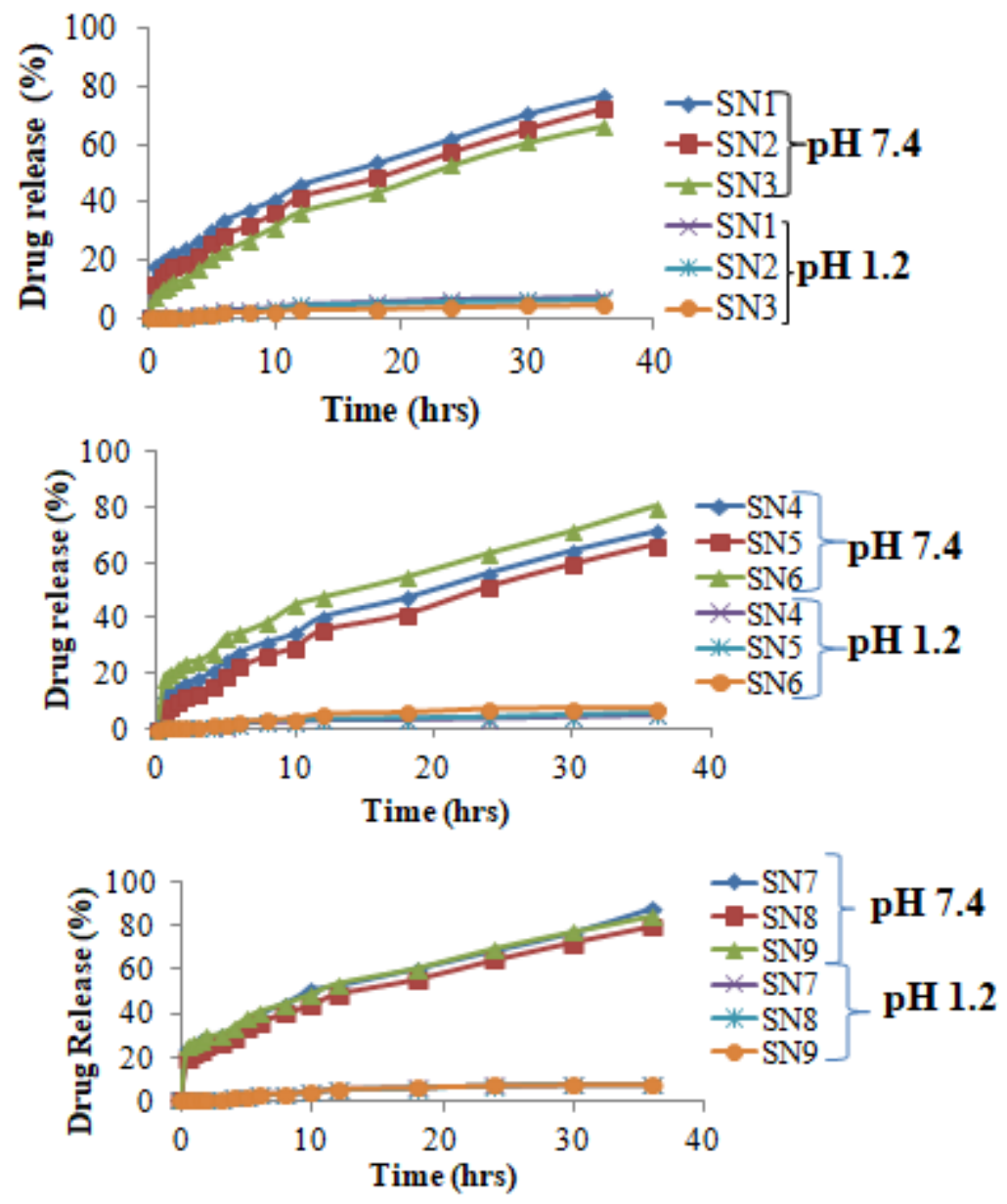

Figure 11. Galantamine hydrobromide release studies from hydrogels (SN1-SN9).

\subsection{Assessment of Galantamine Hydrobromide Release through Kinetic Modeling}

Kinetic modeling was carried out on Galantamine hydrobromide release data to find out release order from HPMC-pectin-co-acrylic acid hydrogel formulations. Zero order, first order, Higuchi, and Korsemeyer-Peppas models were applied for all formulations. Results are shown in Table 3. It was clear from $\mathrm{R}^{2}$ values that Galantamine hydrobromide release from HPMC-pectin-co-acrylic acid hydrogel followed zero order kinetics. First order release kinetics was not supported by the release data. But the other two models, i.e., Higuchi and Korsemeyer-Peppas, supported release data of fabricated hydrogels. Based upon value of " $n$ ", i.e., 0.439 , mechanism of release was Fickian diffusion involving transport of Galantamine hydrobromide solution due to polymer chain relaxation [35].

\subsection{Acute Oral Toxicity Study}

Toxicity studies were carried out to find out the safety level of HPMC-pectin-co-acrylic acid hydrogel. There was no sign of dermal and ocular toxicity and no mortality was observed on administration of prepared hydrogel to tested group. The observation period was 14 days. During this period, no significant 
physical change was observed in both tested and control animals. Blood samples were withdrawn from both groups of rabbits for obtaining complete blood count (CBC), uric acid, liver function test (LFT), and renal function test (RFT) profile. Both sets of animals were sacrificed, and their vital organs were removed for histopathological examination. Results of body weight, water, and food intake are reported in Table 4. Hematological (Tables 5 and 6) and histopathological examination (Figure 12) revealed that HPMC-pectin-co-acrylic acid hydrogel was nontoxic, and there was no specific change observed in the controlled and tested group.

Table 3. Kinetic modeling of release data.

\begin{tabular}{cccccc}
\hline Formulation Code & Zero Order & First Order & Higuchi Model & \multicolumn{2}{c}{ Korsemeyer-Peppas } \\
\hline $\mathbf{R}^{\mathbf{2}}$ & $\mathbf{R}^{\mathbf{2}}$ & $\mathbf{R}^{\mathbf{2}}$ & $\mathbf{R}^{\mathbf{2}}$ & $\mathbf{R}^{\mathbf{2}}$ & $\boldsymbol{n}$ \\
\hline SN1 & 0.9911 & 0.7241 & 0.9715 & 0.9887 & 0.431 \\
SN2 & 0.9907 & 0.7585 & 0.9789 & 0.9902 & 0.426 \\
SN3 & 0.9909 & 0.7909 & 0.9817 & 0.9917 & 0.433 \\
SN4 & 0.9906 & 0.7001 & 0.9630 & 0.9878 & 0.440 \\
SN5 & 0.9908 & 0.7392 & 0.9350 & 0.9848 & 0.405 \\
SN6 & 0.9908 & 0.7921 & 0.9605 & 0.9874 & 0.436 \\
SN7 & 0.9905 & 0.7133 & 0.9165 & 0.9883 & 0.389 \\
SN8 & 0.9901 & 0.6769 & 0.9049 & 0.9852 & 0.377 \\
SN9 & 0.9874 & 0.6679 & 0.8788 & 0.9873 & 0.358 \\
\hline
\end{tabular}

Table 4. Clinical monitoring during oral toxicity studies.

\begin{tabular}{ccc}
\hline Clinical Monitoring & Control Animal Group (A) & Tested Animal Group (B) \\
\hline $\begin{array}{c}\text { Signs of any illness } \\
\text { Body Weight (g) }\end{array}$ & None & None \\
Before treatment & $1653.78 \pm 0.40$ & $1738.91 \pm 0.40$ \\
On Day 1 & $1651.43 \pm 0.60$ & $1735.42 \pm 0.60$ \\
On Day 7 & $1651.39 \pm 0.50$ & $1733.49 \pm 0.40$ \\
On Day 14 & $1650.84 \pm 0.20$ & $1733.64 \pm 0.50$ \\
Food consumption (g) & & \\
Before treatment & $75.87 \pm 3.045$ & $74.28 \pm 2.87$ \\
On Day 1 & $73.49 \pm 2.183$ & $77.93 \pm 1.06$ \\
On Day 7 & $76.48 \pm 4.184$ & $67.85 \pm 3.04$ \\
On Day 14 & $68.98 \pm 3.789$ & $72.48 \pm 3.98$ \\
Water intake (mL) & & $180.62 \pm 2.90$ \\
Before treatment & $200.52 \pm 2.45$ & $187.59 \pm 1.60$ \\
On Day 1 & $190.48 \pm 4.21$ & $204.92 \pm 3.10$ \\
On Day 7 & $195.82 \pm 3.48$ & $200.65 \pm 2.40$ \\
On Day 14 & $203.26 \pm 2.49$ & None \\
Signs of skin allergy & None & None \\
Signs of ocular toxicity & None & None \\
Any mortality & None & \\
\hline
\end{tabular}

For histopathological assessment, histology slide of each vital organ was prepared, and their micrographs were recorded by single blind assessment method. No change was found in the tested group as compared to the control group (Figure 12). Thus, HPMC-pectin-co-acrylic acid hydrogel was found to be nontoxic and safe to living tissues. Cardiac tissues (control and tested) had normal cardiomyocytes without any hypertrophy and inflammation. Liver section of both control and tested groups showed no sign of inflammation and degradation in hepatic cells. Lung section and alveoli were clear without any sign of inflammation and cellular damage. No accumulation of macrophages and other defender cells was found. Spleen section was normal, and their normal shape was retained in both groups of rabbits. In brain section, cells were observed to be normal and neurons were visible with smooth myelin sheath around them. Kidney section revealed that kidneys were normal in both groups. There was no accumulation of inflammatory cells with absence of cellular damage. 
Lastly, histomicrographs of small intestinal section also displayed normal results in both control and tested group.

Table 5. Hematological and biochemical analysis of rabbit's blood.

\begin{tabular}{ccc}
\hline Finding Parameters & Controlled Animal Group (A) & Tested Animal Group (B) \\
\hline White blood cells $\left(\times 10^{3} / \mu \mathrm{L}\right)$ & $4.50 \pm 0.34$ & $5.20 \pm 0.25$ \\
Red blood cells $\left(\times 10^{6} / \mu \mathrm{L}\right)$ & $3.98 \pm 0.49$ & $4.46 \pm 0.51$ \\
Hemoglobin $(\mathrm{g} / \mathrm{dL})$ & $11.93 \pm 0.76$ & $12.86 \pm 0.69$ \\
Platelets $\left(\times 10^{3} / \mu \mathrm{L}\right)$ & $42.63 \pm 0.87$ & $44.52 \pm 0.47$ \\
Lymphocytes $\%$ & $63.10 \pm 0.58$ & $68.70 \pm 0.81$ \\
Monocytes $\%$ & $3.10 \pm 0.35$ & $3.00 \pm 0.21$ \\
Mean corpuscular volume $(\mathrm{fL})$ & $60.90 \pm 2.90$ & $61.40 \pm 2.32$ \\
Mean corpuscular hemoglobin $(\mathrm{pg})$ & $19.90 \pm 0.50$ & $20.90 \pm 0.10$ \\
Mean corpuscular hemoglobin & $35.80 \pm 1.41$ & $33.90 \pm 1.84$ \\
concentration $(\mathrm{g} / \mathrm{dL})$ & & \\
\hline
\end{tabular}

Table 6. LFT and RFT profile of rabbit blood sample.

\begin{tabular}{ccc}
\hline Finding Parameters & Controlled Animal Group (A) & Tested Animal Group (B) \\
\hline ALT(U/L) & $52.45 \pm 1.42$ & $57.28 \pm 1.59$ \\
AST (U/L) & $126.00 \pm 2.33$ & $135.00 \pm 2.84$ \\
ALP (U/L) & $135.00 \pm 1.46$ & $148.20 \pm 1.68$ \\
ALB (g/L) & $5.17 \pm 0.45$ & $4.90 \pm 0.82$ \\
Creatinine (mg/dL) & $0.79 \pm 0.11$ & $0.60 \pm 0.12$ \\
Uric acid (mg/dL) & $2.40 \pm 0.25$ & $2.90 \pm 0.21$ \\
Urea (mg/dL) & $16.02 \pm 0.15$ & $13.50 \pm 0.18$ \\
\hline
\end{tabular}
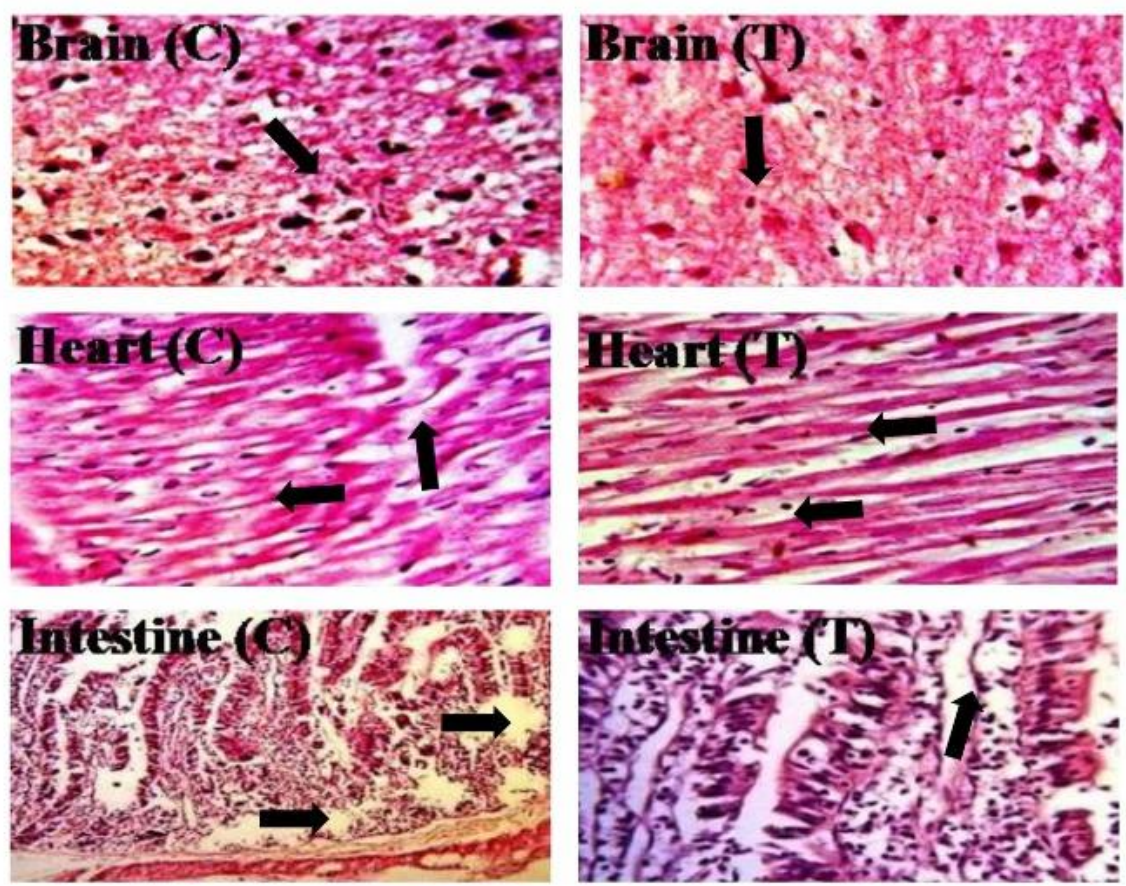

Figure 12. Cont. 

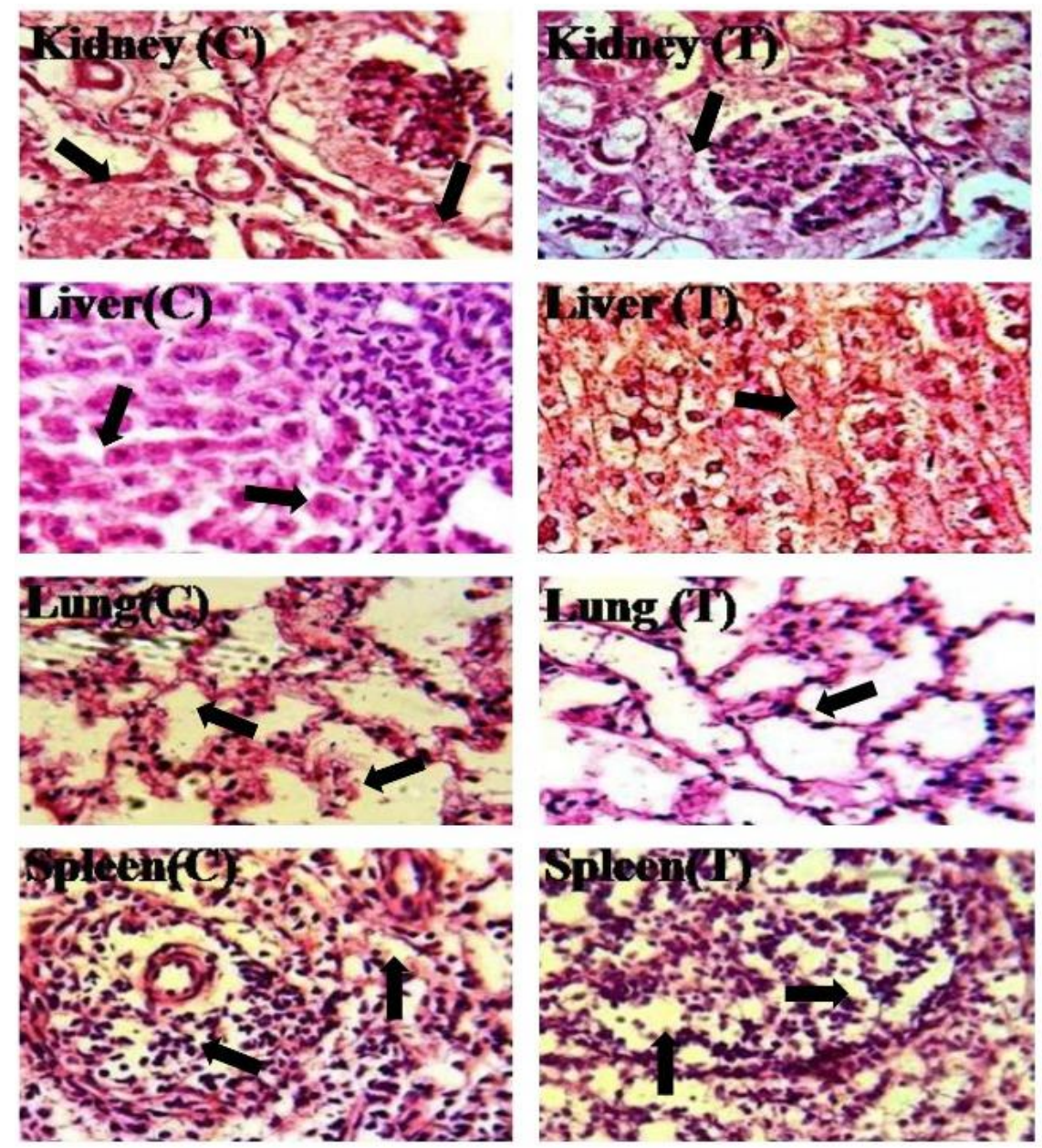

Figure 12. Histopathological examination of vital organs of rabbits.

\section{Conclusions}

HPMC-pectin-co-acrylic acid hydrogels were successfully fabricated through chemically cross-linked method (free radical polymerization technique). Formulated hydrogels showed $\mathrm{pH}$-dependent swelling and release behavior for controlled delivery of Galantamine hydrobromide. Equilibrium swelling percentage was high, i.e., $96.87 \%$ at $\mathrm{pH} 7.4$, whereas, at $\mathrm{pH} 1.2$, up to $10 \%$ swelling percentage was observed. Swelling and release results depends on the amount of pectin, acrylic acid, HPMC, and MBA. As HPMC and acrylic acid amount was increased, swelling and release percentages were observed to be simultaneously increased but not in case of pectin. Higher pectin amount provided higher degree of swelling but lower level of drug release. MBA produced an inverse effect on swelling and release kinetics. The high amount of MBA leads to a lower amount of swelling and release. FTIR, DSC, TGA, and XRD confirmed the complex formation of hydrogel, which was more thermally stable as compared to individual ingredients. Gel fraction results were also directly proportional to HPMC, pectin, acrylic acid, and MBA amount. Mechanical strength of HPMC-pectin-co-acrylic acid hydrogel was excellent having capability to hold out against biological stress. EDX results confirmed loading of Galantamine hydrobromide into formulated hydrogel. In toxicity studies, blood samples and histomicrographs showed that fabricated hydrogel was safe, nontoxic, and compatible to living tissues. It was concluded that formulated hydrogels displayed $\mathrm{pH}$ dependent behavior and smart response to their environmental conditions. Thus, that is why they can be efficiently used in Alzheimer-related dementia where controlled delivery of Galantamine hydrobromide would be provided. Hence, dosing frequency would be reduced, which would ultimately lead to enhanced patient compliance. 
Author Contributions: Conceptualization, N.Z.; methodology, N.L.; software and revision of manuscript, A.M.; validation, S.B., formal analysis, A.E.; investigation, S.B.; resources: S.B., N.Z.; data curation, S.B.; writing original draft, N.Z.; visualization, A.E.; review \& editing, N.L.; supervision, N.Z. All authors have read and agreed to the published version of the manuscript.

Funding: This research received no external funding.

Conflicts of Interest: The authors declare no conflict of interest.

\section{References}

1. Moghanjoughi, A.A.; Khoshnevis, D.; Zarrabi, A. A concise review on smart polymers for controlled drug release. Drug Deliv. Transl. Res. 2016, 6, 333-340. [CrossRef] [PubMed]

2. Gupta, P.K.; Robinson, J.R. Oral controlled-release delivery. In Treatise on Controlled Drug Delivery; Taylor \& Francis group, CRC Press: London, UK, 2017; pp. 255-313.

3. Arslan, M.; Tasdelen, M.A. Click chemistry in macromolecular design: Complex architectures from functional polymers. Chem. Afr. 2019, 2, 195-214. [CrossRef]

4. Robertis, S.D.; Bonferoni, M.C.; Elviri, L.; Sandri, G.; Caramella, C.; Bettini, R. Advances in oral controlled drug delivery: The role of drug-polymer and interpolymer non-covalent interactions. Expert Opin. Drug Deliv. 2014, 12, 441-453. [CrossRef] [PubMed]

5. Moulton, S.E.; Wallace, G.G. 3-dimensional (3D) fabricated polymer based drug delivery systems. J. Controlled Release 2014, 193, 27-34. [CrossRef] [PubMed]

6. Ofridam, F.; Lebaz, N.; Gagnière, É.; Mangin, D.; Elaissari, A. Effect of secondary polymer on self-precipitation of $\mathrm{pH}$-sensitive polymethylmethacrylate derivatives Eudragit E100 and Eudragit L100. Polym. Adv. Technol. 2020, 31, 1270-1279. [CrossRef]

7. Ranucci, E.; Manfredi, A. Polyamidoamines: Versatile bioactive polymers with potential for biotechnological applications. Chem. Afr. 2019, 2, 167-193. [CrossRef]

8. Deen, G.; Loh, X. Stimuli-responsive cationic hydrogels in drug delivery applications. Gels 2018, 4, 13. [CrossRef]

9. Levourch, G.; Lebaz, N.; Elaissari, A. Hydrophilic submicron nanogel particles for specific recombinant proteins extraction and purification. Polymers 2020, 12, 1413. [CrossRef]

10. Grande, D.; Rohman, G. Oligoester-derivatized (semi-)interpenetrating polymer networks as nanostructured precursors to porous materials with tunable porosity. Chem. Afr. 2019, 2, 253-265. [CrossRef]

11. Parhi, R. Cross-linked hydrogel for pharmaceutical applications: A review. Adv. Pharm. Bull. 2017, 7, 515-530. [CrossRef]

12. Gupta, P.; Vermani, K.; Garg, S. Hydrogels: From controlled release to pH-responsive drug delivery. Drug Discov. Today 2002, 7, 569-579. [CrossRef]

13. Moussa, E.; Siepmann, F.; Flament, M.P.; Benzine, Y.; Penz, F.; Siepmann, J.; Karrout, Y. Controlled release tablets based on HPMC:lactose blends. J. Drug Deliv. Sci. Technol. 2019, 52, 607-617. [CrossRef]

14. Raj, A.A.S. A review on pectin: Chemistry due to general properties of pectin and its pharmaceutical uses. Sci. Rep. 2012, 1, 550.

15. Yen, W.F.; Basri, M.; Ahmad, M.; Ismail, M. Formulation and evaluation of galantamine gel as drug reservoir in transdermal patch delivery system. Sci. World J. 2015, 2015, 1-7.

16. Mahmood, A.; Ahmad, M.; Sarfraz, R.M.; Minhas, M.U. $\beta$-CD based hydrogel microparticulate system to improve the solubility of acyclovir: Optimization through in-vitro, in-vivo and toxicological evaluation. J. Drug Deliv. Sci. Technol. 2016, 36, 75-88. [CrossRef]

17. Khanum, H.; Ullah, K.; Murtaza, G.; Khan, S.A. Fabrication and in vitro characterization of HPMC-g-poly(AMPS) hydrogels loaded with loxoprofen sodium. Int. J. Biol. Macromol. 2018, 120, 1624-1631. [CrossRef]

18. Khan, Z.; Minhas, M.U.; Ahmad, M.; Khan, K.U.; Sohail, M.; Khalid, I. Functionalized pectin hydrogels by cross-linking with monomer: Synthesis, characterization, drug release and pectinase degradation studies. Polym. Bull. 2019, 77, 339-356. [CrossRef]

19. Vega-Chacón, J.; Tarhini, M.; Lebaz, N.; Jafelicci, M.; Zine, N.; Errachid, A.; Elaissari, A. Protein-silica hybrid submicron particles: Preparation and characterization. Chem. Afr. 2020, 3, 1-9. [CrossRef]

20. Ouanji, F.; Ellouzi, I.; Kacimi, M.; Ziyad, M. Ca-hydroxyzincate: Synthesis and enhanced photocatalytic activity for the degradation of methylene blue under uv-light irradiation. Chem. Afr. 2019, 2, 395-400. [CrossRef]

21. Hebeish, A.; Hashem, M.; El-Hady, M.M.A.; Sharaf, S. Development of CMC hydrogels loaded with silver nano-particles for medical applications. Carbohydr. Polym. 2013, 92, 407-413. [CrossRef] 
22. Shin, M.-S.; Kim, S.J.; Kim, I.Y.; Kim, N.G.; Song, C.G.; Kim, S.I. Swollen behavior of crosslinked network hydrogels based on poly(vinyl alcohol) and polydimethylsiloxane. J. Appl. Polym. Sci. 2002, 85, 957-964. [CrossRef]

23. Saqib, M.; Bhatti, A.S.A.; Ahmad, N.M.; Ahmed, N.; Shahnaz, G.; Lebaz, N.; Elaissari, A. Amphotericin B loaded polymeric nanoparticles for treatment of leishmania infections. Nanomaterials 2020, 10, 1152. [CrossRef] [PubMed]

24. Mahmood, A.; Sharif, A.; Muhammad, F.; Sarfraz, R.M.; Abrar, M.A.; Qaisar, M.N.; Anwer, N.; Amjad, M.W.; Zaman, M. Development and in vitro evaluation of ( $\beta$-cyclodextrin-g-methacrylic acid)/Na+-montmorillonite nanocomposite hydrogels for controlled delivery of lovastatin. Int. J. Nanomedicine 2019, 14, 5397-5413. [CrossRef] [PubMed]

25. Rehmani, S.; Ahmad, M.; Minhas, M.U.; Anwar, H.; Zangi, M.I.; Sohail, M. Development of natural and synthetic polymer-based semi-interpenetrating polymer network for controlled drug delivery: Optimization and in vitro evaluation studies. Polym. Bull. 2016, 74, 737-761. [CrossRef]

26. Akhlaq, M.; Maryam, F.; Elaissari, A.; Ullah, H.; Adeel, M.; Hussain, A.; Ramzan, M.; Ullah, O.; Danish, M.Z.; Iftikhar, S.; et al. Pharmacokinetic evaluation of quetiapine fumarate controlled release hybrid hydrogel: A healthier treatment of schizophrenia. Drug Deliv. 2018, 25, 916-927. [CrossRef]

27. Hanafy, A.S.; Farid, R.M.; ElGamal, S.S. Complexation as an approach to entrap cationic drugs into cationic nanoparticles administered intranasally for Alzheimer $\backslash$ textquotesingles disease management: Preparation and detection in rat brain. Drug Dev. Ind. Pharm. 2015, 41, 2055-2068. [CrossRef]

28. Feng, L.; Yang, H.; Dong, X.; Lei, H.; Chen, D. pH-sensitive polymeric particles as smart carriers for rebar inhibitors delivery in alkaline condition. J. Appl. Polym. Sci. 2017, 135. [CrossRef]

29. Ibrahim, A.G. Synthesis of poly(acrylamide-graft-chitosan) hydrogel: Optimization of the grafting parameters and swelling studies. Am. J. Polym. Sci. Technol. 2019, 5, 55-62. [CrossRef]

30. Mittal, N.; Kaur, G. In situ gelling ophthalmic drug delivery system: Formulation and evaluation. J. Appl. Polym. Sci. 2013, 131. [CrossRef]

31. Hastuti, B.; Mudasir, M.; Siswanta, D.; Triyono, T. Preparation and $\mathrm{Pb}(\mathrm{II})$ adsorption properties of crosslinked pectin-carboxymethyl chitosan film. Indones. J. Chem. 2015, 15, 248-255. [CrossRef]

32. Tan, H.L.; Tan, L.S.; Wong, Y.Y.; Muniyandy, S.; Hashim, K.; Pushpamalar, J. Dual crosslinked carboxymethyl sago pulp/pectin hydrogel beads as potential carrier for colon-targeted drug delivery. J. Appl. Polym. Sci. 2016, 133. [CrossRef]

33. Wang, T.; Chen, L.; Shen, T.; Wu, D. Preparation and properties of a novel thermo-sensitive hydrogel based on chitosan/hydroxypropyl methylcellulose/glycerol. Int. J. Biol. Macromol. 2016, 93, 775-782. [CrossRef] [PubMed]

34. Yoshinobu, M.; Morita, M.; Sakata, I. Porous structure and rheological properties of hydrogels of highly water-absorptive cellulose graft copolymers. J. App. Polym. Sci. 1992, 45, 805-812. [CrossRef]

35. Ouyang, L.; Highley, C.B.; Rodell, C.B.; Sun, W.; Burdick, J.A. 3D printing of shear-thinning hyaluronic acid hydrogels with secondary cross-linking. ACS Biomat. Sci. Eng. 2016, 2, 1743-1751. [CrossRef]

Publisher's Note: MDPI stays neutral with regard to jurisdictional claims in published maps and institutional affiliations.

(C) 2020 by the authors. Licensee MDPI, Basel, Switzerland. This article is an open access article distributed under the terms and conditions of the Creative Commons Attribution (CC BY) license (http://creativecommons.org/licenses/by/4.0/). 